\title{
Análisis jurídico de la globalización desde la perspectiva del Derecho comercial internacional ${ }^{1}$
}

\author{
LiZETH JULiAnA GARCÍA ATRA ${ }^{2}$ \\ EDUARDO CALDERÓN MARENCO ${ }^{3}$
}

\section{RESUMEN}

El Derecho, al igual que la sociedad, ha sufrido el fenómeno evolutivo procurando cobijar en cada una de sus manifestaciones las diversas y nuevas formas de comportamientos o acciones que surgen de las relaciones humanas, políticas, sociales, ambientales, estatales, entre otras; el comercio y la economía no son indiferentes a estas nuevas regulaciones, pues, además de tratarse de unas de las actividades más antiguas de la humanidad que despliega su ejercicio más allá de las fronteras territoriales de un Estado, genera indudables beneficios económicos directos a cada Estado. Dicho lo anterior, es menester acorar que gran parte de la economía saludable de un país requiere del intercambio de bienes y servicios para satisfacer necesidades primarias, y, en segundo término, los Estados y sus ciudadanos requieren que estos intercambios comerciales se expandan más allá de su territorio para obtener bienes que no estén al alcance de las producciones nacionales, o bien, para adquirir materias primas que resultan en productos acabados. Es entonces que este artículo procurará esbozar los cambios más contundentes que ha generado el fenómeno de la Globalización con especial énfasis en el Derecho del comercio internacional. Para tal efecto, se plasmará un estudio de las principales posiciones doctrinarias con el ánimo de esquematizar dos elementos fundamentales en este ámbito: armonización y unificación; métodos que han aportado a un Derecho global del comercio, con el fin de

1 Fecha de recepción: 26 de septiembre de 2018. Fecha de aceptación: 30 de enero de 2019. Para citar el artículo: García Atra, L. y Calderón Marenco, E. (2019). Análisis jurídico de la globalización desde la perspectiva del Derecho comercial internacional, en Revista Con-texto, n. ${ }^{\circ}$ 51, pp. 15-53. DOI: https:// doi.org/10.18601/01236458.n51.03.

2 Magíster en Derecho por la Universidad Autónoma del Estado de Morelos, Especialista en Derecho Administrativo por la Pontificia Universidad Javeriana, correo-e: lizethjuliana_523@hotmail.com

3 Candidato a Doctor en Derecho por la Universidad Centroamericana (UCA) y Universidad Externado de Colombia mediante el programa de co-tutela, maestro en Derecho y Negocios Internacionales por la Universidad Iberoamericana de la Ciudad de México, correo-e: eduardo.caldero.marenco@gmail.com 
contribuir a un proceso que ha iniciado hace poco o, por lo menos, cuyo acento y velocidad se han tornado magníficos en tiempos recientes, gracias a factores fundamentales, como las nuevas tecnologías y los componentes informáticos.

Palabras clave: Globalización; Derecho comercial internacional, Unificación; Armonización; Estados.

\section{LEGAL ANALYSIS OF GLOBALIZATION FROM THE PERSPECTIVE OF INTERNATIONAL COMMERCIAL LAW}

\section{ABSTRACT}

The Law, like society, has suffered an evolutionary phenomenon trying to cover in each of its manifestations, the diverse and new forms of behaviors or actions that arise from human, political, social, environmental and state relationships, among others; commerce and economy are not indifferent to these new regulations, because, in addition to being one of the oldest activities of humanity that displays its exercise beyond the territorial borders of a State, it generates undoubted direct economic benefits to each State. That said, it is necessary to accept that a large part of a country's healthy economy requires the exchange of goods and services to meet primary needs, and, secondly, states and their citizens require that these commercial exchanges expand beyond its territory to obtain goods that are not within the reach of national productions, or to acquire raw materials that result in finished products. It is then that this article will attempt to outline the most forceful changes that the phenomenon of Globalization has generated with special emphasis on the international commercial law. In order to do so, a study of the main doctrinal positions will be expressed so as to outline two fundamental elements in this area: harmonization and unification; these methods have contributed to a global commerce law for providing a process that has recently begun or, at least, whose accent and speed have become magnificent in recent times, thanks to fundamental factors, such as new technologies and computer components.

Keywords: Globalization; International Commercial Law; Unification; Harmonization; State.

\section{INTRODUCCIÓN}

El fenómeno de la Globalización ha impactado considerablemente los escenarios político, social, económico y jurídico, entre otros; de hecho, esto ha dificultado la expedición y comprensión de una definición unívoca de este concepto. Este proceso, además, ha favorecido ostensiblemente la ampliación de espacios económicos y el desarrollo tecnológico; lo anterior, sin perjuicio de que desde esa óptica se ha dado paso a la modificación de las leyes y a la desnacionalización de los mercados. 
Es por lo enunciado que en estas líneas se pretenderá el estudio del impacto del proceso de Globalización desde una perspectiva jurídica, entendiendo además que su desarrollo ha tenido seguidores y detractores, concretamente, en el ámbito económico, toda vez que se ha sostenido doctrinalmente que se ha transformado en un instrumento que beneficia a ciertas personas, que ha entorpecido la materialización de una real liberalización comercial (en especial, con las crisis económicas que han tenido lugar en estos últimos años) y que evidencia una ausencia de compromiso serio con las normas internas del Estado gracias al desarrollo y constante crecimiento de este fenómeno.

No obstante, como se expondrá en este escrito, la concepción de Estado ha mutado, atendiendo a las reglas de competencia de mercado, dando lugar a la cesión de la soberanía, en especial, cuando se ha favorecido el reconocimiento de instituciones jurisdiccionales de orden internacional y teniendo en cuenta la notoria expansión del comercio de carácter trasnacional; lo enunciado ha conducido al surgimiento de una Globalización jurídica. Igualmente, la realidad del comercio internacional que conlleva la comercialización de productos y servicios en distintos escenarios del planeta ha hecho necesaria la creación de sendas normas y leyes en el orden jurídico interno y mundial que den tratamiento a la materia, con miras a la seguridad jurídica, especialmente, en materia de contratación internacional.

En estas condiciones, se ha acudido a la unificación y armonización del Derecho comercial internacional (advirtiendo, en todo caso, sus características especiales y que las hacen diferentes entre sí), como herramientas útiles para la creación y aprobación de normas y regímenes jurídicos que coadyuven al desarrollo del comercio internacional, especialmente, con la expedición de normas y documentos de carácter técnico que puedan aplicarse a nivel interno en los Estados, buscando así el fortalecimiento de estos, pretendiéndose asimismo la uniformidad de las prácticas comerciales internacionales; en todo caso, estos procesos unificadores y armonizadores han presentado sendas dificultades en la práctica, concretamente, en el ámbito de adaptación a los sistemas jurídicos estatales.

A los inconvenientes enunciados se suma la carente actualización de la codificación y legislación existente en materia comercial en el orden internacional, que además genera incertidumbre frente a la aplicación de normas en casos en los que existen vínculos contractuales; es justamente aquí donde surge la necesidad de crear disposiciones armónicas y unificadoras que concilien las diferencias de los distintos ordenamientos jurídicos, disminuyendo la inseguridad para las partes y favoreciendo la coordinación del tráfico jurídico en el orden internacional.

\section{EL DERECHO Y LA GLOBALIZACIÓN}

\subsection{Aproximación conceptual a la Globalización}

¿Qué es la Globalización? Primeramente, Vengoa (2002) concluye que es un proceso que ha dado lugar a la constitución de espacialidades temporalizadas, entendidas como 
redes de interpenetración que pueden ser económicas, sociales, políticas y/o culturales, que trascienden las fronteras reales o imaginarias

Por su parte, De Souza Santos (1998) enfatiza que es un fenómeno polifacético con dimensiones económicas, sociales, políticas, culturales, religiosas y jurídicas, combinadas de la maneras más complejas; además, debido a su complejidad, variedad y amplitud, el proceso de Globalización está conectado a otras transformaciones en el sistema mundial que, sin embargo, no son reducibles a él, tales como la creciente desigualdad a nivel mundial, la explosión demográfica, la catástrofe ambiental, la proliferación de armas de destrucción masiva, la democracia formada como condición de asistencia internacional a países periféricos y semiperiféricos, entre otros.

López Daza (2003) manifiesta que la Globalización implica un fenómeno, inicialmente económico y posteriormente cultural y jurídico, que afecta indiscutiblemente la vida de casi todos los seres humanos; este fenómeno se puede representar en algunos ejemplos como la corriente protectora de los Derechos del Hombre iniciada con la Revolución Francesa en 1789, la lucha contra la monarquía absoluta y contra el despotismo de los gobernantes.

A pesar de que los ejemplos vertidos no son recientes, puede encontrarse en ellos la manifestación de la Globalización, pese a que Kaplan, citado por García Flores (2013), sitúa la creación del término en la década de los ochenta entre científicos sociales, ideológicos, periodistas, políticos, gobernantes, administradores, dirigentes corporativos y representantes de grupo de interés y de presión, empero, la popularización del término va acompañada de una gran variedad de contenidos y significados, atribuidos, imprecisos y contradictorios, por la falta del modelo teórico que permita confrontar las diferentes manifestaciones e interpretaciones. Así, se habla de una Globalización económica, jurídica, política, cultural, ambiental, de los medios de comunicación, tecnológica, y un sinfín de áreas a las que es posible aplicarla, por lo que puede hablarse de una pluralidad de Globalizaciones que denotan el hecho de que las fronteras estatales se han ido difuminando, para que sean ingresados al territorio estatal todo tipo de productos, de personas y de servicios; de que el ser humano o el Estado pueden realizar todo tipo de operaciones, no solo comerciales, al otro lado del mundo sin moverse de su lugar de origen, a través de internet; que los medios de comunicación han logrado dar a conocer lo que ocurre en otras partes del mundo, en algunos casos, en el momento en que suceden.

Se afirma que existe desde el inicio de la humanidad y concretamente a partir del momento en que los grupos humanos empezaron a entrar en relación, intercambiando experiencias culturales que se entremezclaron, generando una simbiosis de costumbres y culturas, que se incrementa cada vez más, y especialmente en las últimas décadas a raíz de los avances tecnológicos (Vásquez Vásquez, 2009). A pesar de que su expresión sea relativamente nueva, su impacto abarca todos los aspectos de la sociedad humana, tanto a escala general como particular, y se entrevera en todos los sectores del quehacer del hombre. Claramente, es un fenómeno que se va dando de forma paulatina, en algunos casos en forma espontánea, y, en otros, dadas ciertas condiciones de relación entre diver- 
sas sociedades organizadas, como una imposición generada desde los centros del poder hacia las periferias dominadas: así lo enuncia Beck, citado por Vásquez Vásquez (2009).

Sin temor a equívocos, este término siempre ha estado ligado al desarrollo tecnológico y económico, tal y como lo afirma López Guzmán (2011), para quien la Globalización es en primer lugar y ante todo un proceso económico, pero, además, financiero, científico y tecnológico, cuyas nuevas tecnologías de la información y la comunicación han tejido alrededor del mundo una red de enlaces tan densos como flexibles. De la misma manera, Dávalos Torres (2010) comparte que la Globalización nació como un fenómeno económico caracterizado por los siguientes elementos: a) movimiento de personas de un país a otro, b) flujo de capitales de un país a otro (inversión extranjera) y c) desarrollo acelerado y democratización de las telecomunicaciones.

Es claro que dentro de estos procesos surgen distintos escenarios y actores, que en gran medida han permitido la ampliación de espacios económicos, la mayor intercomunicación de todos los agentes sociales, el desarrollo tecnológico y el comercio. En virtud de los argumentos de Rodríguez Fernández (2016), se puede enunciar que la Globalización, efectivamente, se presenta como un proceso, o una serie de procesos, que incorporan un fenómeno cultural cuya manifestación es consecuencia de la apertura y la integración económica, y que se promueve al interior de los países industrializaciones y las instituciones que estos crearon para tal fin, instituciones internacionales que han procurado una mayor integración de los temas que atañen al globo, económicos, políticos, culturales, tecnológicos, ambientales, entre otros; con toda seguridad, se puede manifestar que es el fenómeno social más característico de finales del siglo XX que coincide con el final del milenio, y lo seguirá siendo muy probablemente durante las primeras décadas del siglo XXI y del tercer milenio.

Globalización, en definitiva, implica actualmente un asunto de localización o de fragmentación o, en definitiva, de resurgimiento de lo local frente a lo que se postula o se impone como global o universal, aunque suene paradójico, es que se vive en una común "aldea global", pero se está condenado, cual una hermosa torre de Babel, a convivir con lenguajes diferentes (Fariñas Dulce, 2008). Carbonell Sánchez (2003) explica de mejor manera en qué consiste tal afirmación:

Algunos autores señalan este doble efecto de la Globalización (hacia arriba, pero también hacia abajo) y sostienen que sería mejor hablar de glocalización, para dar cuenta de la combinación de energías que señalan tanto hacia una efectiva supra nacionalización (que incluye el desvanecimiento de las fronteras políticas o incluso físicas entre los países), como hacia una vuelta al localismo (en forma de desmembración de Estados, de movimientos secesionistas, de mayores demandas de autonomía política de las regiones, de políticas y reivindicaciones multiculturalista, etcétera) (p. 160).

Ya se ha advertido que el fenómeno es complejo, compuesto por varias estructuras. La primera estructura o elemento fundamental es la eliminación de barreras económicopolíticas a la libre circulación de factores productivos. La segunda estructura o elemento 
es el proceso de desarrollo tecnológico sin precedentes de las comunicaciones físicas y de las telecomunicaciones, lo que permite un desplazamiento fluido de personas, información, y de modelos culturales y sociales por todo el mundo (Carrascosa González, 2004).

Por último, para concluir este entramado conceptual, Grün (2003) ubica a la Globalización como un proceso, al igual que todos los demás, pero que genera la desnacionalización de los mercados, las leyes y la economía. Es decir, interrelaciona, interconecta diversos sistemas sociales de distinta envergadura. A todas luces, con base en las opiniones brindadas por todos los autores, es posible concluir que, evidentemente, no existe una uniformidad sobre lo que se llama Globalización, y solamente se destaca que emerge de la evolución del hombre y de ciertas actividades que implican su interacción con otros sujetos ajenos a su Estado-nación, como las comunicaciones, las tecnologías, la economía, el Derecho y el comercio, entre otras; sin embargo, no todos concuerdan en que dicho fenómeno asegure un bienestar o desarrollo positivo para las sociedades; por tanto, se considera oportuno conocer algunas de estas posiciones que desaprueban su existencia.

\subsection{Efectos adversos de la Globalización}

Inicialmente, debe apuntarse a que precisar si la Globalización es mala o buena, va a depender en sí mismo de la ideología personal, así como de las posiciones políticas adoptadas por cada Estado, que en lo particular todo proceso que conlleve un mayor desarrollo y que a la vez signifique bienestar social debe ser catalogado como positivo; claro está que estribará en la posición del aparato estatal y las necesidades de sus gobernados, y es que el éxito o fracaso del modelo globalizador no obedece a la forma como está concebida sino a la manera en que se aplica, por tanto, según López Guzmán (2003), el triunfo de una Globalización con rostro humano residirá en entender primeramente las necesidades locales, la cultura y las costumbres de una región o un país, para así amoldar la teoría económica a la realidad social, dado que de forma incuestionable una de sus facetas es una realidad económica irreversible.

La Globalización tiene sus más fieles seguidores y sus más enconados críticos. Quienes se adscriben a las teorías simpatizantes ven con buenos ojos la internacionalización de la economía y las empresas, pues lógicamente encuentran que en medio de la libre competencia el beneficiario principal es, sin duda, el consumidor, y es que, teniendo ante sí el infinito de posibilidades que le ofrece el mercado sobre distintos bienes y servicios, goza del sagrado derecho de libertad de elección, el cual le asiste también en lo político, lo religioso y lo cultural. De manera más concreta, esto se obtiene mediante el libre mercado, tildado por algunos como un recurso imperialista o neoliberal, por lo que los detractores de estas posturas -mercado neoliberal- sustentan sus críticas esencialmente en el hecho de que la liberalización solo se hace en beneficio de los países desarrollados, generando desempleo, crisis y pobreza en países en vías de desarrollo; además, se da un mayor distanciamiento en materia de desarrollo tecnológico con respecto a los países súper industrializados; sin embargo, concatenado con el Derecho de libre elección del 
individuo y el consumidor, sin un libre mercado los productos en una economía en vías de desarrollo serían pocos, es decir, un abanico escaso de opciones.

Maya Muñoz, citado por López Guzmán (2003), elocuentemente enfatiza las deficiencias del modelo de la Globalización, de la siguiente manera:

La Globalización no es un fenómeno nuevo. Con las premisas de que se mejora la eficiencia económica y se logra un crecimiento económico mayor, la Globalización como política económica busca tanto la liberalización comercial como la financiera: solo un mercado, un solo precio. El mercado de trabajo, a escala internacional, se exceptúa del libre movimiento de la fuerza de trabajo. Los países desarrollados solo son generosos con las inmigraciones cuando el ciclo de negocios las hace una necesidad (p. 23).

Puede interpretarse de lo enunciado por Maya Muñoz que la Globalización puede ser un instrumento de unos pocos y a merced de los intereses económicos de un mercado centralizado o único manejado por ciertos actores; en este mismo tenor, Alonso Soto (2001) se suma a estas reflexiones, tomando en cuenta que los Estados, persiguiendo sus sentidos nacionalistas y proteccionistas, pueden mermar el desarrollo de este proceso (liberación del mercado) adoptando medidas como políticas reguladoras que limiten el funcionamiento de los mercados (así, por ejemplo, la necesidad de disponer de una autorización administrativa para operar, el establecimiento de condiciones para el ejercicio de la actividad, el sometimiento a diversos controles, etc.); mantenimiento de áreas de actividad reservadas con carácter exclusivo a algunas empresas públicas o privadas, de forma que solamente ellas podrán actuar en el correspondiente mercado; el establecimiento de medidas gubernamentales de política comercial, tales como la regulación de las importaciones, el fomento de las exportaciones, el control de cambios, la protección de las pequeñas y medianas empresas; la realización de prácticas contrarias a la libre competencia por parte de algunos empresarios, que consideran más ventajosa una política de concertación que el sometimiento a las reglas del mercado, con el agravante añadido de que, al transformarse las empresas en multinacionales, las prácticas también se internacionalizan.

Todos estos supuestos ponen en peligro, sin lugar a dudas, la pretendida liberalización comercial; sin embargo, el Estado puede fundamentar su actuar argumentando que la permisión de libre mercado lleva a la creación o instauración de grandes consorcios que tienden a erosionar las culturas nacionales, a crear necesidades artificiales a través de publicidad y a manipular, seleccionando la información y trastocando las necesidades del receptor. La Globalización (dicen algunos) es un instrumento del imperialismo para mantener al tercer mundo en la miseria; un peligro para las culturas nacionales, un factor que debilita enormemente la capacidad de actuación de los Estados. Otros afirman, por el contrario, que esa misma Globalización ayuda a expandir en el mercado un nivel de vida más alto (Martí Borbolla, 2005).

Muchos de los países en vías de desarrollo también se han beneficiado de ese proceso a través de la liberación y apertura de sus economías, aunque se señala con muy fuertes 
argumentos que han sido más los perjuicios causados que los beneficios recibidos. Solo en los últimos tiempos se ha presenciado cómo las crisis financieras globales afectan de manera particular a los países en vía de desarrollo, con lo que una vez más se prueba que el capitalismo y, a su lado, la Globalización representan la ya vieja idea de privatización de las garantías, para los agentes económicos de los países desarrollados, y la socialización de las pérdidas para los que estamos buscando el desarrollo (Rodríguez Fernández, 2016).

En este orden de ideas, se tiene que el debate acerca de la Globalización se ha enfocado sobre todo en los medios que se pueden sustraer del fenómeno para hacer que el mismo sea un mecanismo de ayuda para el desarrollo de todos los países. Sin embargo, otros consideran que al aceptar la ideología global se constriñe la habilidad de los gobiernos de proteger a sus ciudadanos, especialmente aquellos que sufren los costos de los cambios en la configuración de las redes internacionales de producción; siempre el temor se enraíza en factores económicos, empero, no son los únicos argumentos que se erigen en contra de este fenómeno porque de igual forma se habla de la pérdida de los atributos propios del Estado mediador y regular de los conflictos del modelo Keynesiano del siglo $\mathrm{XX}_{\text {; }}$ pero también de la progresiva destrucción de algunos elementos constitutivos de la soberanía estatal, tal y como se había configurado desde el origen de la edad moderna.

Fariñas Dulce (2008) y Rodríguez Fernández (2016) consideran a la Globalización como un nuevo intento de homogeneizar la pluralidad o una nueva forma de neutralizar y controlar las diferencias que amenazan a la imposición de dicho modelo civilizatorio. Vinculado a esto, es necesario asentar que esta nueva forma de homogeneización y de dominación universalista instrumentaliza a su favor el principio jurídico de la igualdad meramente formal, el universalismo jurídico y el discurso de unos derechos del hombre de carácter liberal e individual, como fundamento de su propia legitimidad formal. Ello conlleva el rechazo a cualquier otro tipo de Derechos humanos, que pudieran atentar contra la libertad y la ideología neoliberal del mercado, es decir, todos aquellos derechos que tengan un contenido de protección social, económica y cultural de los individuos, o un contenido redistributivo o igualitario. Por ello, no tiene un efecto neutral, sino que repercute negativamente sobre los niveles de protección de los denominados derechos sociales, económicos y culturales y los derechos colectivos en general, perjudicando, por tanto, a los estratos sociales más desprotegidos (Fariñas Dulce, 2008, p.188).

Un argumento más que señala Fariñas Dulce (2008) en contra va dirigido a la imposición de una desterritorización y una descentralización del proceso decisorio estatal, afirmando que ahora son los mercados financieros los que toman las decisiones y los gobiernos estatales, los que las gestionan y ejecutan. Por lo tanto, en la medida que el proceso decisorio va siendo descentralizado, desterritorializado y transnacionalizado, las decisiones políticas se toman condicionadas por equilibrios macroeconómicos que representan, más que un mero indicador, un verdadero principio normativo responsable de la fijación de rigurosos límites a las intervenciones reguladoras de los Estados nacionales.

Sin embargo, se considera que este argumento se desvanece frente a los procesos integracionistas regionales, e incluso es posible aseverar que la Globalización tiende a una restructuración político-administrativa de las regiones que propenden por sistemas 
de integraciones políticas, económicas, entre otras. Tal es el caso de la Unión Europea, Mercosur, Centroamérica, por poner algunos ejemplos, dado que esta tendencia procura un nuevo modelo tanto de gobierno como de comercio que unifica o armoniza las políticas económicas y de mercado para tener un frente común antes las diferencias que presentan con otras regiones del globo.

Por último, para terminar estos argumentos antiglobalizadores, debe manifestarse que para algunos críticos férreos, la Globalización conlleva aspectos negativos al ámbito jurídico, dado que la ideología del mercado, que invade las relaciones transnacionales, genera también una ausencia de compromiso con las normas estatales internas, tomando en cuenta que en muchas ocasiones las normas imperativas de los Estados no son adecuadas para regular este tipo de transacciones, es decir que no existe regulación para las nuevas relaciones jurídico-económicas transnacionales; no obstante, se considera que en este plano no resulta negativa la influencia de la Globalización, dado que en el desarrollo de campos jurídicos transnacionales se encuentran regulaciones que contribuyen a establecer límites y controles a la actividad productiva de las actuales empresas transnacionales, que, como ya se ha dicho, escapan a las tradicionales regulaciones internas de los Estados.

\subsection{El impacto del fenómeno globalizador en el Derecho. A propósito de la} Globalización jurídica

\subsubsection{Globalización y Estados}

En el ámbito internacional, el sujeto de Derecho por antonomasia pasó a ser el Estado, no la persona ${ }_{i}$ las cosas quedaron reducidas a derechos y deberes interestatales y a la manera de resolver los conflictos entre Estados. Esta afirmación ha quedado superada actualmente, debido a la importancia que está cobrando de nuevo la persona en el ordenamiento internacional, y al hecho de que la humanidad, a causa de la Globalización, se ha configurado, al menos incidentalmente, como comunidad política (Domingo Osle, 2005); además, el individuo ha pasado a ser un actor en la creación de normas en el plano internacional, lo que lo ha obligado a modificar el paradigma estatista ilustrado, ya obsoleto, por uno cosmopolita que incluya al individuo como garante y creador de derechos. Muchos son los pasos que se han dado en esta dirección, especialmente a partir de la declaración Universal de Derechos Humanos. Para los ordenamientos jurídicos, este movimiento en doble dirección ha supuesto la necesidad de ir construyendo nuevos paradigmas; tal como apuntan García Flores (2013) y Carbonell Sánchez (2003), lo que se persigue es crear nuevas facilidades de acceso a los aspectos de la vida que trascienden las fronteras, por ejemplo el comercio, lo cual no significa que el proceso de Globalización pretenda eliminar las fronteras nacionales, sino flexibilizar su comportamiento, lo cual no era permitido por la rigidez soberana del Estado.

Es así que las atribuciones estatales cuya esencia deriva del concepto de soberanía se han modificado, mayormente se acentúa la facultad legislativa, así como en el ejercicio de la soberanía estatal sobre instituciones gubernamentales, dado que la intrusión en la 
vida nacional de nuevos actores, internos e internacionales, en las actividades económicas de la nación, ha dado una nueva dimensión de gobierno, se insiste, la alteración no significa desaparición.

Tal como lo dice Flores Enciso (2006): "La Globalización es una tendencia irreversible. Es innegable que ha incrementado el comercio y que ello ha implicado mayor inversión, con productividades crecientes, impulsando el crecimiento y el empleo en los países que lideran este proceso" (p. 35), y por ende, el Estado debería ser garante de estos beneficios económicos que conlleva el avance globalizador, considerando permear sus fronteras so pena de aislamiento.

Es valedero enunciar que el Estado está mudando su piel, ahora se transforma, adquiere nuevas facetas y desafíos en medio de la complejidad, que construye el juego que la Globalización económica y financiera, la expansión de los mercados, las delicadas operaciones transnacionales, a las que poco importan las fronteras estatales; en este espacio en el que circulan los flujos de capitales, entonces el Estado se convierte en un actor más que participa de las reglas de la competencia que el mercado establece y en donde se prescinde del mismo porque parece marginarse de la dinámica que plantea la economía global, como hacedor de pautas sociales, como bien lo ha dicho Arévalo Mutiz (2008); además, esto lo que genera es un replanteamiento del rol y las tareas del Estado, lo que no supone la desaparición del mismo, sino que, por el contrario, invita a observar un cambio, una transformación en sus competencias y nuevos retos en su devenir.

El desempeño de las funciones económicas sugiere nuevos acuerdos que emanan de actores diferentes al mismo Estado, normatividades que transforman el panorama de la soberanía nacional tradicional, presentando una forma de crear Derecho que soslaya al estatal y que es ajena a una mirada jurídica monolítica, tradicional. El Estado es relevado, no en su totalidad, por normas creadas a través de nuevos sujetos y poderes económicos privados, pero también, por la aparición de jerarquías y jurisdicciones, como es el caso de instituciones como el arbitramento internacional y organismos encargados de solucionar controversias surgidas de acuerdos entre las partes, y en algunas ocasiones, por acuerdos multilaterales de los mismos Estados relevando su poder soberano de decidir el Derecho.

Desde este punto de vista, se puede decir que el Derecho o su creación también se ven influenciados por la Globalización, aunque ciertamente, como se enunció con anterioridad el término Globalización es moderno; sin embargo, en todas las épocas se pueden encontrar vestigios de este fenómeno, en particular en el ámbito jurídico, como lo enuncia López Guzmán (2003), que desde el Derecho romano se hayan vivenciado los mismos presupuestos que estructuran el concepto de Globalización jurídica, tal es el caso que mientras hoy el predominio se sustenta en el libre juego de fuerzas del mercado, impuesto por la gran empresa capitalista trashumante, que no conoce barreras legales impuestas por los Estados soberanos, el gran influjo global del imperio romano estaba fundado en el poderío político y militar.

Otro aspecto relevante se encuentra en coincidencias tales como la fragmentación de soberanías; en el papel del juez como creador de Derecho, el cual facilita una solución equitativa y justa a un hecho en controversia, igual a como ocurre en el Comon law de los 
ingleses. Se enuncia además el pluralismo de fuentes, es decir, que todo el Derecho no proviene del Estado en sí mismo, y que sus instituciones no son las únicas legitimadas para administrar justicia; la pluralidad de centros, lo que se traduce en que todo el Derecho no está cimentado en una estructura piramidal; y que el Estado no es en sí mismo el epicentro del quehacer jurídico. Es conocido que, tras la Segunda Guerra Mundial, se crearon organismos como la Organización Mundial de Comercio ${ }^{4}$ (OMC), el Fondo Monetario Internacional ${ }^{5}$ (FMI) y el Banco Mundial ${ }^{6}$ (BM), que trazan el horizonte económico global y determinan los intereses privilegiados en sus agendas; estos organismos son un ejemplo claro de cesión de soberanía, de cara a la toma de decisiones en el ámbito económico. Resulta interesante recoger la reflexión realizada por Zagrebelsky, citado por Arévalo Mutiz (2008), quien no duda al afirmar que

El Derecho se está transformando en los tiempos modernos, abandonando la idea de "Estado fuerza" que se impone sobre todo aquello que está bajo su dominio y que posee la competencia para ser el único creador legítimo de las normas, hecho que al ser contrastado con la nueva realidad nos conduce a un concepto de Estado que cambia a partir de "fuerzas corrosivas". Desde finales del siglo pasado actúan fuerzas corrosivas, tanto interna como externamente: pluralismo político y social interno, que se opone a la idea misma de la soberanía de sujeción;

4 La OMC es la organización internacional y única de su tipo que se ocupa de las normas que rigen el comercio entre los países. Los pilares sobre los que descansa son los Acuerdos de la OMC, que han sido negociados y firmados por la gran mayoría de los países que participan en el comercio mundial y ratificados por sus respectivos parlamentos. La OMC nació el 1 de enero de 1995, pero su sistema de comercio tiene casi medio siglo de existencia. Desde 1948, el Acuerdo General sobre Aranceles Aduaneros y Comercio (GATT) ha establecido las reglas del sistema. La segunda reunión ministerial de la OMC, celebrada en Ginebra en mayo de 1998, incluyó un acto de celebración del 50ªniversario del sistema. No pasó mucho tiempo antes de que el Acuerdo General diera origen a una organización internacional de facto no oficial, conocida también informalmente como el GATT. A lo largo de los años, el GATT evolucionó como consecuencia de varias rondas de negociaciones. La última y más importante ronda del GATT fue la Ronda Uruguay, que se desarrolló entre 1986 y 1994 y dio lugar a la creación de la OMC. Mientras que el GATT se había ocupado principalmente del comercio de mercancías, la OMC y sus Acuerdos abarcan actualmente el comercio de servicios, y las invenciones, creaciones y dibujos y modelos que son objeto de transacciones comerciales (propiedad intelectual).

5 El Fondo Monetario Internacional (FMI) (Internacional Monetary Fund) fue creado en 1945. Su origen se remonta a "La Conferencia Monetaria y Financiera Internacional de las Naciones Unidas y Asociadas" realizada en 1944, cuyas resoluciones adoptadas por los Acuerdos de Bretton Woods delimitaron ciertas reglas para el funcionamiento de la economía internacional, con el fin de evitar una nueva crisis como la ocurrida en 1929 y asegurar cierto crecimiento sostenido y paridad entre las naciones. Estados Unidos, gran acreedor de la Segunda Guerra Mundial, fue el que impulsó su creación. En los finales de la Segunda Guerra Mundial, muchos países estaban a punto de ser derrotados, América Latina era permeable a las decisiones de Washington y el bloque Comunista participó en la conferencia, pero no ratificó el acuerdo.

6 El Banco Mundial (BM) tiene sus orígenes en 1944, cuando se inició como un organismo para hacer préstamos a países, se daba seguimiento y recomendaciones a las economías de los países asociados. Los préstamos iban enfocados al desarrollo y la reconstrucción de las ciudades afectadas durante la Segunda Guerra Mundial. 
la formación de centros de poder alternativo y concurrentes con el Estado, que operan en el campo político, económico, cultural y religioso (p. 81).

Sobre esta aseveración debe reflexionarse que a simple vista la soberanía está siendo menguada por el avance impetuoso de la Globalización, con todo, más bien se afirma que se está frente a un nuevo modelo, la reconceptualización de la soberanía que debe atender a la influencia de otros Estados, así como el cambio de la idea de territorio, como una forma de romper todo tipo de frontera territorial y de dibujar un nuevo mapa de lo global que propenda a una liberalización del comercio, o bien, a una Globalización jurídica de cara a un ámbito comercial más integrado en el plano internacional.

A manera de corolario, se comparte lo evocado por Clerc (2013), dado que el concepto geopolítico de frontera nacional, al menos como categoría articuladora de la soberanía con eje en lo territorial, se ha visto erosionado en sus fundamentos a partir de la notable expansión experimentada por el comercio transnacional, y de ahí que el alcance jurídico y normativo se está rediseñando para concebir un nuevo sistema jurídico internacional basado en un modelo que prescinda de los ordenamientos nacionales favoreciendo, en primer lugar, la proliferación de normas de uso, contextualmente generadas según intereses de parte, las cuales son impuestas luego por la sociedad internacional como parámetros indicativos y/o directrices objetivas desde las cuales se deben resolver las controversias interpartes que puedan suscitarse; en segundo lugar, haciendo que la actividad comercial transnacional se concentre siguiendo las líneas de fuerza trazadas por las hegemonías económicas preexistentes, dejando por fuera del juego económico global a numerosos actores comerciales que no gozan de las ventajas competitivas que detentan las empresas concentradas y los grandes consorcios, por lo que es menester el abordaje de las transformaciones jurídicas en el plano del comercio internacional, a su vez influenciadas por la Globalización.

\subsubsection{Derecho comercial internacional y Globalización}

La Globalización de los mercados invita a tornar la mirada hacia las nuevas regulaciones jurídicas que requieren estas actividades; en otras palabras, a la regulación de la Globalización misma, pero a la vez, observar las influencias que han tenido estas (regulaciones jurídicas) derivadas de estos acontecimientos globales. El comercio internacional pretende la desaparición selectiva de las fronteras nacionales ${ }^{7}$; a esto le corresponde una manifes-

7 Selectiva, en este contexto, querría decir que las fronteras desaparecen para unos efectos, pero no para otros. Desaparecen o tienen a desaparecer -o a atenuarse-, por ejemplo, para el tránsito de mercancías; en ese contexto surgen los acuerdos de libre comercio, el levantamiento de barreras arancelarias, entre otros. Pero las fronteras no desaparecen respecto de otros fenómenos. Uno de esos fenómenos que ocupa la atención de juristas interesados en la Globalización, tiene que ver con la posibilidad de que se resuelvan por la jurisdicción los conflictos derivados de actos relacionales con un comercio global y, dentro de este, los del denominado comercio justo. Así, por ejemplo, dentro de la agenda de temas jurídicos de interés desde este punto de vista, se encuentran el arbitraje internacional, el Derecho de 
tación jurídica precisa siendo que las nuevas tendencias reconocen la multiplicidad de niveles de Derecho, pero se enfoca más en tres: el global, el nacional y el sub nacional (Twining, Guardiola Rivera y Sandoval Villalba, 2003).

Dicho esto, se considera que la actividad comercial ha gozado de una mayor influencia por parte de este proceso, por lo que su reglamentación jurídica también lo ha experimentado; si bien es cierto, en estricto sentido, que el comercio siempre ha sido una actividad lucrativa que consiste en la intermediación directa o indirecta entre productores y consumidores, con el objeto de facilitar y promover la circulación de la riqueza (Castrillón y Luna, 2011), no obstante, su evolución siempre se ha visto influenciada por los constantes cambios y demandas sociales, desde la antigua Lex Mercatoria hasta su codificación ${ }^{8}$.

los tratados, la posibilidad de existencia y límites de un constitucionalismo global, o la inacabada -e inacabable- discusión sobre la existencia o inexistencia de un orden jurídico válido en todo tiempo y lugar (Aramburo Calle, 2013, p. 85).

$8 \quad$... A manera de instrucción podemos decir que en la génesis y evolución del comercio se distinguen tres etapas, a saber: el trueque, la menda y el crédito. La etapa relativa al trueque se caracteriza por el intercambio de mercancías elaboradas por los productores, que cumplen como función única la de proporcionar satisfactores, sin importar de modo especial la calidad de aquellas, si bien se toma en cuenta la cantidad... Barrera Graff, por su parte, distingue cuatro etapas en la formación del Derecho mercantil: la primera, de la Edad Media hasta el Código de Napoleón, que llamaríamos etapa urbana del comerciante individual especializado y matriculado en gremios y corporaciones; la segunda, de los códigos de comercio basados en el acto de comercio a partir de Napoleón, de 1808; la tercera, de las leyes y códigos mercantiles estructurándose en torno a la actividad empresarial, y la cuarta, aún en formación, con la tendencia a la incorporación de nuevas disciplinas, tales como el Derecho mercantil internacional, el marítimo y el económico. El Derecho mercantil inicialmente surge en torno de la figura del comerciante, propiciando, así, como derivación de sus uso y prácticas, el nacimiento de un Derecho comercial subjetivo de carácter consuetudinario, tanto sustantivo como adjetivo, que con la intervención de los gremios de comerciantes se desarrollan en función de las actividades que los mismos realizan y que con el tiempo es complementado con el aporte de diversos elementos de carácter objetivo, como son las iniciales regulaciones de la actividad comercial, normadas a través de las ordenanzas y estatutos, y que son posteriormente completadas con los decretos. Así, dice Rafael de Pina que el Derecho mercantil nace en la Edad Media y es de origen consuetudinario, que el auge del comercio, el desarrollo del cambio y el crédito fueron las causas que originaron la multiplicación de las relaciones mercantiles de modo que el Derecho mercantil está ligado íntimamente a la actividad de los gremios o corporaciones de mercaderes que se organizaban por estatutos que recogían las practicas mercantiles (Castrillón y Luna, 2011, pp. 3, $6,7)$.

Por otro lado, tenemos también que existen consenso en la doctrina de que, en la gestación del Derecho mercantil, podemos distribuir tres momentos históricos bien diferenciados: a) Una primera etapa, caracterizada por el dominio de una concepción subjetivista del Derecho comercial, donde este era el Derecho de los comerciantes en el ejercicio de su actividad profesión, y que se extendió desde la Edad Media hasta la Revolución Francesa. b) Una segunda, que se manifiesta en el periodo comprendido entre la sanción del Código Francés en 1807 y los comienzos del siglo XX, caracterizada por el predominio de una concepción objetivista, como disciplinaria de los actos de comercio. c) Finalmente, una tercera, aún subsistente, que retorna a una concepción predominante subjetivista, en el cual no se concibe acto de comercio que no sea realizado por el comerciante, y donde la institución de la empresa desempeña un papel preponderante en el tráfico mercantil. A pesar de que ya el en el Código de Hammurabi (2080 a.c.) hallamos preceptos relacionados al préstamo con intereses, al contrato de deposito, al de comisión, así como también relativos al transporte y a formas precarias de sociedad, el Derecho comercial en el 
Es claro que, en el ámbito de la economía, cabe señalar que la realidad del comercio internacional viene impuesta por la distribución de productos y servicios en las diferentes regiones del planeta con una fuerza expansiva tal, que no reconoce fronteras; frente a tal realidad, para hacer congruente la normatividad que va surgiendo en el ámbito internacional y lograr una mayor y mejor seguridad jurídica se ha evidenciado la necesidad de que los países que participan de dicho concierto internacional realicen adecuaciones necesarias en sus regímenes internos independientemente de la región o país, en donde se localicen (Torres Manzo, 1961). Dice Arcelia Quintana, citada por Castrillón y Luna (2011), también respaldado por los fundamentos de Domingo Osle (2009), que la Globalización de los principios rectores del libre mercado ha puesto a los Estados-Nación ante dos grandes retos: por un lado, normar toda actividad, relaciones y procedimientos que se generen entre los actores del mundo comercial, $y$, por el otro, que esas normas formen parte de un Derecho comercial internacional ${ }^{9}$ (o, como algunos doctrinarios le conocen, Derecho mercantil internacional), con el cual se armonice la regulación de los

sentido propio, como rama autónoma, no tiene sus orígenes en las civilizaciones de los pueblos orientales antiguos. Solo en germen lo encontramos en la antigüedad clásica. En la edad antigua y especialmente durante el dominio de Roma, existieron previsiones de naturaleza mercantil fragmentarias que, a pesar de haber llegado a un importante grado de perfección y completividad, jamás conformaron cuerpos normativos ordenados sistemáticamente. Roma era esencialmente mercantilista, que comerciaba con la mayor parte de los pueblos del mundo conocidos en aquel entonces. Existía el comercio, pero no el Derecho comercial. En un primer momento, las primitivas operaciones mercantiles no se regulaban sino por las normas propias del ius civile. La caída del imperio Romano de Occidente, un proceso que duró diez siglos, obedece a varias causas. Con ella se quebró la unidad jurídica de la Europa Romana. Los pueblos bárbaros, empujados por los hunos, penetraron en lo que quedaba de las ciudades y organización romana, originando una transferencia cultural que alteró los hábitos, costumbres y el ordenamiento jurídico general entonces imperante (Marzorati, 2003, p. 2).

9 Desde una perspectiva histórica conviene retener que hasta 1945 el comercio internacional se caracterizaba por una dimensión estatal de los poderes económicos privados, fuertemente apoyados por la política expansionista de los Estados de donde procedían. Hasta entonces el número de dichos Estados era muy reducido: aquellos en donde la acumulación de capital en capital financiero, como consecuencia de la Revolución Industrial, había propiciado una política de expansión internacional, a saber, Francia, Gran Bretaña, Estados Unidos. Mas, a partir de 1945, fue menester la adopción de un orden normativo capaz de responder al reto de un cambio radical en las relaciones económicas internacionales. El régimen de comercio ya no respondía al esquema demoliberal de economías estatales que en el plano internacional se traducía en tres principios básicos, los cuales, con mayor o menor intensidad, estuvieron presentes a lo largo de todo el pasado siglo en las disposiciones internas de los Estados, y en la generalidad de los convenios de comercio. En primer lugar, el principio de libre cambio, vencedor del proteccionismo que había caracterizado el periodo anterior e indispensable para el desarrollo de las transacciones internacionales. En segundo lugar, el principio de libertad de comercio, fiel reflejo del liberalismo económico proclamado por la revolución francesa. Por último, el principio de igualdad de trato entre el extranjero y el nacional en materia mercantil. El comercio internacional comprende al mundo entero como campo de actuación y queda, por tanto, bajo la esfera de intervención de organismos internacionales, de carácter universal o regional. Por ello el ordenamiento regulatorio de esta realidad jurídica de naturaleza transnacional coarta, prima facie, la posibilidad del legislador estatal de determinar con entera libertad las respuestas jurídicas a estas transacciones de acuerdo con su propia concepción de justicia (Fernández Rozas, 1996, p. 35). 
intercambios económicos, las transferencia de tecnología, el libre comercio, los contratos internacionales y el comercio internacional de bienes y servicios.

Domingo Osle (2009), de igual manera, citando al jurista vienés Hans Kelsen, enfatiza que la Globalización ha provocado la internacionalización del Derecho; es por ello que la ordenación jurídica global va más allá de la celebración de tratados internacionales por parte de los Estados, dado que no solo estos (Estados) se globalizan, sino también la sociedad, reclamando una clara participación en el quehacer de las normas jurídicas que ahora rigen las relaciones comerciales.

Ahora bien, podría pensarse que en el mundo del Derecho la Globalización se ha limitado a modificar las prácticas de los sectores del ordenamiento jurídico vinculados con el comercio exterior, lo cierto es que ha cambiado casi todos los ámbitos. Hoy en día se construye (con todas las dificultades inherentes) un proceso de Globalización del Derecho penal. Paradójicamente, la Globalización genera no solo prácticas supranacionalizadoras, sino también efectos disgregadores hacia el interior de cada EstadoNación, lo que significa que puede no ponerse una venda en los ojos ni cruzar los brazos ante los cambios inminentes que requieren las actividades globales.

Asertivamente, Restrepo Uribe (2003) recuerda que ahora los mercados son globales, sus reguladores tienen que serlo también, igualmente Ortega et al. (2008) integran en sus reflexiones que los agentes económicos que participan en el mercado internacional de bienes y servicios y realizan transacciones internacionales están influenciados de manera determinante por el marco legal aplicable para definir el riesgo legal y los costos atribuibles a los sistemas jurídicos involucrados; esto propicia un mayor desarrollo de los negocios en un ambiente de seguridad jurídica. Ante ese nuevo contexto social y económico, se hace patente que los modos de regulación ya no cumplen su cometido y que el Derecho ya no tiene la misma capacidad de asegurar la función para la cual se había instituido como modo privilegiado de regulación social (Latorre, 2016).

Como se ha sostenido a lo largo de estas líneas, la Globalización ha permitido la creación y desarrollo del Derecho mercantil internacional ${ }^{10}$, una realidad contempo-

10 Consideramos acertado lo expuesto por Ravassa Moreno (2004), debe hablarse de un Derecho mercantil internacional que comprende un abanico de disposiciones que podemos sintetizar así: en primer lugar, como base de sustentación original, las normas de Derecho constitucional económico y de los códigos y leyes mercantiles, junto a las viejas normas para regular conflictos de leyes o reglas de colisión entre diferentes ordenamientos estatales; estas normas requieren de adaptación a las nuevas situaciones creadas por la comunidad internacional; sigue inmediatamente el Derecho uniforme internacional que los diferentes Estados pueden adoptar mediante tratados, convenciones o poniendo en vigor en su territorio leyes modelos, cuyo contenido ha sido fijado previamente por organismo internacionales; entran igualmente las normas de Derecho derivado y obligatoria aplicación procedentes de las organizaciones regionales de países, a las que también se ingresa por los tratados; continúa la relación con las disposiciones elaboradas pero el concierto de sujetos que intervienen en el tráfico internacional y por los organismos privados, como los usos y prácticas, guías jurídicas, formularios de contratos, condiciones generales de contratación, etc. de carácter internacional, tales como INCOTERMS, y finaliza esta relación con las decisiones de los tribunales internacionales.

Por su parte, Castrillón y Luna (2011, pp. 71-74) tildan tradicionalmente el Derecho mercantil como una rama del Derecho conjuntamente que, con el civil, integra las dos grandes vertientes del Derecho 
ránea de la que no es posible sustraerse. La ley o el Derecho por la cual se rigen los comerciantes de hoy no es exclusivamente la local, pues, como es lógico, los negocios actuales trascienden fronteras cotidianamente (López Guzmán, 2003). El Derecho es parte de la Globalización, o cacaso la Globalización del Derecho no es un fragmento de su esencia? Asimismo, los elementos supranacionales son un reflejo de la denominada democracia cosmopolita.

privado. Podríamos decir que el Derecho mercantil se mantiene en el ámbito del Derecho privado en lo relativo a las relaciones domésticas, esto es, cuando se trata de la vasta regulación que a través de los años ha sido formado por los órganos legislativos estatales, y es útil y adecuada a las relaciones internas, aun cuando desactualizadas en algunos aspectos. No obstante, la creación de las normas elaboradas por un organismo internacionales a los que hemos referido líneas atrás, para dar respuesta al fenómeno de la Globalización, ha provocado el desplazamiento de nuestra disciplina hacia el campo del Derecho internacional privado, de modo que estamos en presencia de un Derecho supranacional. Tal situación se presenta cuando, por la acción de las empresas trasnacionales, y los avances tecnológicos, la disciplina regula relaciones de comercio internacional, porque en cada supuesto, como hemos ya visto, las regulaciones internas de los Estados resultan inadecuadas y obsoletas a las necesidades del tráfico de mercaderías en el comercio exterior. En tal escenario, el Derecho mercantil debe ser ubicado como parte del Derecho internacional privado, porque esta disciplina regula, entre otras muchas instituciones, las relaciones de los particulares en lo internacional, a que se ha desplazado el Derecho del comercio por la acción global de los organismos internacionales, que, en respuesta al fenómeno global y mediante la creación de normas de carácter, en su conjunto han sido emitidas para la seguridad a las relaciones de la sociedad empresarial en el ámbito internacional. Finalmente, y evidente aproximación de las tendencias actuales del contenido del Derecho internacional privado de manera concreta con el Derecho mercantil internacional, dice Arellano que a aquel le corresponde decidir en norma jurídica qué debe prevalecer y agrega que la evolución futura de la disciplina y haga llegar al extremo de dejar de aplicar las reglas de Derecho de órdenes jurídicos nacionales y tiene cabida a una regla de Derecho uniforme (como ocurre de manera evidente con el Derecho mercantil internacional) y que para que se tal situación se realicen se requiere: un legislador internacional que creara normas de Derecho en las diversas ramas, $y_{;}$en defecto de ese legislador, una convención internacional obligatoria para los Estados, cuyas normas pretendan vigencia, que parecieran disposiciones normativas de fondo en las diversas materias. Refiriéndonos de manera directa al Derecho mercantil internacional, cabe señalar, siguiendo a Barrera Graf, que es una parte del Derecho mercantil que regula las transacciones comerciales que se celebran entre diferentes países y entre partes residentes en dos o más de ellos a través de disposiciones, leyes, convenciones sentencias por autos dictados por tribunales nacionales e internacionales.

La Res. de la A.G. de las N.U. 2012 (XX) del 20 de diciembre de 1965 que define el Derecho del comercio internacional sobre la base de tres elementos. 1) Materia regulada: se trata de un ordenamiento regulador de las relaciones comerciales internacionales, compraventa internacional, instrumentos negociables, seguros, operaciones de transporte, propiedad industrial, propiedad literaria y arbitraje comercial ${ }_{i}$ 2) Carácter privado: esta concepción también concibe el Derecho del comercio internacional como el conjunto de normas que rigen las relaciones comerciales de naturaleza de Derecho Privado, que comprenden diferentes países, y 3) Carácter uniforme: el Derecho del comercio internacional así concebido trata de configurar, en palabras de Schmitthog, un nuevo ius mercatorum como un parte del Derecho internacional privado, dedicado no a resolver conflictos de leyes, sino a evitar su presentación por medio de la uniformidad jurídica. De ahí que se vaya a la búsqueda de la uniformidad con un técnico sustantivita de inspiración internacional que pusiera el acento en el principio de la uniformidad de las soluciones y dejaba de lado la tendencia de imponer en el plano internacional las concepciones jurídicas propias del ordenamiento nacional (Fernández Rozas, 1996, p. 41). 
El Derecho es una ciencia que se desenvuelve con el desarrollo de la Globalización; en definitiva y acertadamente como acercamiento a la problemática jurídica planteada, la Globalización no es un simple proceso económico-político, sino que también es un verdadero proceso jurídico (Sánchez Torrez, 2011), que reclama un fuerte papel en la transfiguración de los conceptos fundamentales más tradicionales, una revolución jurídica, por así decirlo; para Ravassa Moreno (2004), el debilitamiento de la autoridad del Estado frente al auge de lo local y lo trasnacional con la decadencia del concepto tradicional de soberanía y, el resurgimiento de una fuerza inusitada en el principio de la autonomía de la voluntad, impulsa u obligan a una reconsideración general del tema jurídico. La Globalización jurídica ha comenzado por el intento de fusionar sistemas jurídicos muy diferentes y, en algunos sentidos, opuestos, verbigracia, el sistema angloamericano o sistema de Common Law y el sistema continental europeo.

Para los ordenamientos jurídicos, este movimiento globalizador supone la necesidad de ir construyendo nuevos arquetipos jurídicos, aunque la realidad muestra que ha sido más lento el proceso de configuración jurídica de un orden supra nacional, pues parte de la lógica que han impuesto las grandes empresas a los distintos procesos de Globalización es exigir a los gobiernos la más amplia libertad para el movimiento de capitales, lo que se traduce como falta de normas de acción.

Todo esto conlleva hablar, precisamente, de la necesidad de globalizar el Derecho, concepto con el que se quiere señalar el proceso a través del cual el mundo entero puede llegar a convivir bajo un mismo grupo de reglas. En el escenario del incremento del comercio internacional, se hace cada día más necesaria la adopción de leyes o normas transnacionales que regulen esa materia, que suplan de manera eficiente las necesidades de los agentes del comercio internacional y que les otorgue un reconocimiento a las operaciones que realizan, campo que pertenece al Derecho mercantil internacional, por ende la Globalización del Derecho en su vertiente comercial debe ser vista, entonces, como un proceso concomitante con la Globalización de los mercados y las prácticas negociables de las corporaciones multinacionales que operan en esos mercados (Rodríguez Fernández, 2016).

En efecto, de manera más amplia se anota que los espacios del tiempo presente parecen ser los espacios abiertos del mercado, del comercio, de la economía y las finanzas libres, del intercambio de circulación de objetos y personas; espacios que propone un Derecho nuevo, sin barreras, sin fronteras o por fuera de ellas, y que han hecho pensar en un sistema jurídico que no tenga ya un determinado territorio, como su centro propio de existencia y referencia, un Derecho que, por lo mismo, esté en irremediable conflicto con el positivismo jurídico ligado al Estado.

El efecto de los procesos globalizadores en el Derecho convierte las fronteras soberanas en zonas de interacción e interrelación entre el orden jurídico interno y el orden jurídico internacional ${ }^{11}$, sobre lo cual se puede hacer alusión a una nueva realidad jurídica

11 El orden jurídico internacional es un fenómeno social destinado a regular las relaciones y dirimir los conflictos que se presentan dentro de su competencia espacial. Cada Estado edifica su propia pirámide 
global. Y es que, gracias a la Globalización jurídica, es posible asistir a la instauración de un nuevo espacio internacional caracterizado por la creación de una línea de interacción entre la jurisdicción internacional y las soberanías internas, surgida pues, como consecuencia del fenómeno. Es acertado lo que expresa Clerc (2013), Globalización jurídica, un fenómeno estructural y sistémico ${ }^{12}$, entendiendo por ello, un proceso que ejerce efectos orgánicos sobre conglomerados, mecanismos, dispositivos, instituciones, agentes, prácticas, valores, entre otros, y no ya sobre estructuras aisladas.

Contreras, referido por Jiménez Benítez (2011), expresa que las transformaciones jurídicas que origina la Globalización traen consigo procesos de modernización con una urgencia de ajuste estructural al interior del Estado, y, hacia el exterior, el diseño de unas políticas de inserción transnacional en el que se equilibra la soberanía interna con un orden jurídico que posibilite la competencia global y promueva la emergencia de otros actores como protagonistas de la jerarquía normativa. En este nuevo ordenamiento, no solo los Estados pasan a ser sujetos del Derecho internacional: también lo

normativa, y esto es posible porque se le reconoce entidad soberana, capaz de crear e imponer el orden jurídico al interior de cada nación. El orden jurídico internacional, en una perspectiva moderna, evidencia una transferencia de soberanía de los Estados en su favor, que podría llevar a replantear el modo tradicional de producción del Derecho. Esto ha llevado a la doctrina a reestudiar el concepto de soberanía legislativa y jurisdiccional, a la luz de estos nuevos desarrollos, los cuales no habrían sido posibles si el orden internacional continuara con las tradicionales limitaciones, ampliamente expuestas por estudiosos, en particular, el problema de su aplicación. Desde una perspectiva clásica, la norma internacional, sea que tenga como destinatarios a los Estados o a los particulares, será considerada como obligatoria, bien con apoyo en una concepción voluntarista del Derecho internacional que encuentra en el concepto de soberanía la facultad de autolimitación de los Estados y de allí la fuerza obligatoria de la norma (tesis positivista), o bien en la constatación objetiva de la existencia de necesidades sociales incontestables que hacen del Derecho internacional un Derecho vinculante (tesis objetivista). En esa perspectiva clásica, la falta de órganos judiciales de alcance internacional aptos para reestablecer el orden jurídico alterado encuentra otras formas de solución en el plano de la responsabilidad internacional y en el uso legítimo de contramedidas de cualquier índole, en lo que hace al Derecho público, o en la ejecución local de fallos y laudos extranjeros previo trámite de revisión, en el dominio privado. A esta aproximación tradicional al problema de la fuerza vinculante de la norma internacional se contraponen nuevas tendencias: por un lado, la existencia de tratados de normas materiales con vocación universal y de fallos internacionales con efectos locales directos, y el uso de cada vez más frecuente pro parte de actores de la sociedad internacional de códigos de deontología y escenarios de autocomposición, de otra parte (Zapata de Arbeláez, 2003, p. 47).

12 La Globalización posee contenidos estructurales y de sistematicidad. Estructurales, porque gradualmente se va consiguiendo una concatenación de contenidos en la evolución del capitalismo hacia la formación de una economía mundial, en la que los centros de poder van asegurando legislaciones universales de carácter obligatorio, como los acuerdos multilaterales de la Organización Mundial del Comercio para el comercio internacional, o reglas universales para la economía, como las que maneja y supervisa el Fondo Monetario Internacional y manejarán otros organismos que se empiezan a configurar para hacer el seguimiento a los fenómenos que condujeron a la crisis financiera internacional de 2008. Por su parte, se habla de contenidos de sistematicidad porque la Globalización produce consistencia espacial y de tiempo en los fenómenos del proceso, que no van a ser circunstanciales, ocasionales o fortuitos, sino interpenetraciones sistemáticas y duraderas gracias a la afirmación de unas espacialidades territoriales y unas temporalidades interdependientes que dan origen a un tiempo mundial (Vieira Posada, 2011, p. 671). 
son los pueblos y los individuos, más precisamente el comerciante o empresario, quienes surgen en el ámbito internacional como actores transnacionales, al igual que los organismos no gubernamentales que generan una sociedad heterogénea, ajena al control territorial y político del Estado. Es indispensable tener en cuenta que, para entender el fenómeno jurídico internacional, hay que pensar en términos dinámicos; no puede, en efecto, concebirse el Derecho como un conjunto normativo cristalizado en una forma determinada, sino como algo en constante transformación para adaptarse a la realidad cambiante, sobre todo en el plano internacional. Se ha dicho, con razón, que el Derecho sigue a la realidad comercial y para que pueda seguirla con eficiencia, es necesario que la siga con oportunidad.

Se quiere igualmente apuntar de manera más concluyente a que, así como la cesión de soberanía del Estado no implica la desaparición del mismo, de esa manera acontece con la Globalización del Derecho que no significa la eliminación de los sistemas jurídicos nacionales, sino su complementación, adecuación y armonización con diferentes órdenes jurídicos de carácter regional, estatal, supraestatal y global. La Globalización y relocalización no significan la desaparición, por ahora, del Estado nacional, sino su transformación y adecuación al nuevo orden. Insistimos: esta apertura depende de cada Estado, aunque es viable afirmar que tarde o temprano el desarrollo económico que se persigue demandará una adecuación a las nuevas formas que pauta las tendencias globales. Al respecto, Carbonell Sánchez (2003) afirma que

La Globalización económica pasa a ser la causa y la base para llegar a la Globalización del Derecho. A su vez, tras las referencias a lo económico, la llegada a la Globalización jurídica se asume de dos formas. La primera, como una realidad que se encuentra presente. Es decir, el Derecho global aparece como una situación de hecho generada por los cambios en el mundo económico y que produce la aparición de nuevos sujetos crea-dores de derecho ajenos al poder de los Estados. La segunda, como la posibilidad de generar (crear) un Derecho global, entendiéndolo como una alternativa a la Globalización económica o como una propuesta. Así, esta opción comprende dos versiones; la primera entendería que el Derecho global (del punto anterior) tiene algunos efectos negativos que deben ser enfrentados por un Derecho global alternativo, y la segunda propone la creación de un Derecho global como una respuesta de adaptación del Derecho internacional a los nuevos escenarios globalizantes. Cualquiera de las dos formas anteriores, indistintamente se han referido al Derecho global para derivar de ahí un marco jurídico uniforme y armónico o, por el contrario, un espacio de fragmentación, no armónico. Independientemente de que sea o no así, las tendencias a caracterizar la Globalización como fragmentación o uniformidad también pueden ser producto del predominio dado a la Globalización económica (p. 207).

De esta misma manera, Oviedo Albán (1999) exterioriza que, frente al fenómeno de Globalización de las relaciones económicas, es necesario pensar en la creación de unas reglas jurídicas ágiles, aplicables a todos los sistemas sociales, políticos y económicos con las que se dote de seguridad y agilidad a las mencionadas transacciones. Un ejem- 
plo de esto viene dado por nueva Lex Mercatoria (término del cual nos ocuparemos en el segundo acápite) o Derecho mercantil internacional, manifestada en contratos estándar, prácticas comerciales reconocidas por los actores del tráfico, usos o costumbre, códigos de conducta, reglas y principios reconocidos y recomendados por organizaciones internacionales, entre otros; esto son manifestaciones de un Derecho uniforme, creado a la luz de la fuerte influencia globalizadora en el comercio que demanda una regulación pronta y adecuada, que a toda luz no esté vinculada a las regulaciones tradicionalista de los Estados, que en muchas ocasiones no responden a estas realidades.

Ahora bien, la Globalización jurídica en el plano mercantil mediante las acciones tradicionales del comercio, despliegan su actuar en el campo internacional; por tanto, los mecanismos de contratación internacional constituyen herramientas indispensables en un mundo que hoy está basado en las relaciones de intercambio comercial global, con el nuevo orden internacional dinámico que despierta relaciones mercantiles y de otra clases con diferentes actores del globo $;$ el tráfico jurídico se amplió y se intensificó con la participación de un mayor número de protagonistas de diferentes culturas jurídicas, lo que generó que naciera un ordenamiento propio del comerciante internacional que otorgara seguridad a sus agentes y enriqueciera con soluciones nuevas las situaciones conocidas y aquellas que no tenían antecedentes (Romero Erazo,1998).

En la actualidad, todos los países están vinculados en diferentes medidas a la actividad comercial internacional, por lo que entran en contacto ordenamientos disímiles; por lo tanto, las fuentes del Derecho mercantil internacional constituyen un elemento vital para evitar conflictos. Adquieren valor preponderante los acuerdos internacionales, regionales, multilaterales, convenios, tratados e inclusive la costumbre, lo que se traduce en un Derecho uniforme, o bien, en la armonización del Derecho mercantil internacional.

La unificación de las reglas jurídicas internacionales en materia comercial es una respuesta de la comunidad internacional que busca la creación de un lenguaje común para facilitar el intercambio de bienes y servicios y capitales. Dentro de este proceso de interacción de reglas jurídicas internacionales, el tratamiento uniforme de situaciones y problemas presupone un entendimiento mínimo en cuanto a lo que significan los distintos conceptos en juego, lo que trae como consecuencia que se eviten discusiones superfluas y que además se exprese un sistema racional, común con respeto de las costumbres comerciales generalizadas; así lo participan Romero Erazo (1998) y Jerez Riesco (2007); además las operaciones comerciales internacionales exigen a las nuevas regulaciones que recojan el conocimiento de las nuevas técnicas comerciales y los métodos operativos compatibilizados para despejar incertidumbres, simultáneamente que se gana en confianza, rutina y profesionalidad de las nuevas exigencias y demandas que imponen los tiempos contemporáneos, cuando las comunicaciones, por una parte, ayudan a fortalecer las relaciones económicas.

Para ir finiquitando este entramado de ideas, está claro el efecto que ejerce la Globalización en el Derecho y en el Estado; esto conduce al abordaje de las principales manifestaciones o acciones que se presentan en el espacio del Derecho mercantil internacional, o mejor dicho, como se manifiesta este nuevo Derecho. Ya ha sido posible un 
acercamiento a esta temática, tomando en cuenta que la uniformidad y armonización son las acciones más contundentes que se reflejan en esta realidad del mundo, dado que contienen una continua creatividad en el ámbito de los contratos, necesaria para atender circunstancias negociables cada vez más dinámicas y cambiantes, que requieren ser resueltas sobre la marcha. Estas innovaciones, con sus reiteraciones, generan usos y costumbres que desembocan en la tipicidad consuetudinaria y que conducen, cuando el legislador lo considera conveniente, en la tipicidad normativa.

Para cerrar este apartado, debe entenderse, entonces, que lo que atañe aquí es el desarrollo jurídico de las nuevas tendencias globalizadoras del espacio comercial, por ejemplo, la compraventa mercantil. Es precisamente en este contexto en donde todavía está vigente la concepción clásica a la que se ha hecho alusión (Farina, 2005). En cambio, en aquellos casos en los que hay un enfrentamiento a una de aquellas operaciones comerciales en donde la relación que nace de la voluntad de las partes se considera o refuta internacional, o es un fruto del nuevo contexto social y económico creado como consecuencia de la Globalización, esta deberá someterse al estudio de un régimen jurídico apropiado o propio de este tipo de relaciones. Régimen que no puede seguir la vieja concepción a la que ya se ha hecho referencia y que debe dar paso a la flexibilización de las normas que regulan la materia, en lo que hoy se ha denominado por algunos Derecho comercial internacional.

Con ello se pretende señalar que la intervención del Estado en este campo se debe enfocar en el reconocimiento de un nuevo entorno económico y jurídico, y en su regulación. Es evidente que el contrato en la esfera internacional tiene unas características propias que lo diferencian de aquel concebido a nivel local o nacional. Esos rasgos característicos son producto de la Globalización en general, y en particular de la congruencia de diversas culturas. En pocas palabras, el contrato internacional requiere de una regulación en este plano, más cuando las construcciones jurídicas por virtud de la evolución social, económica, política, cultural y jurídica y de los asombrosos progresos tecnológicos han sido superadas en todas las latitudes: el estatuto del mercader y los actos aislados de comercio ya no son la médula de este sector del Derecho privado nacional. Sin ánimos de entrar a detalles, el comercio electrónico, las redes informáticas y la constante configuración de nuevas formas de relación contractual o empresarial han determinado cambios en la mentalidad, criterios, prácticas y, como es lógico, adaptaciones del Derecho positivo a través de la uniformidad o armonización, ambos desde el punto de vista internacional (Narváez García, 1995).

Además de esto, es necesario resaltar que el comercio internacional busca una reducción de los costes de transacciones jurídicas; para estos casos es necesario un ordenamiento jurídico común a los operadores del mercado internacional que dé seguridad a las transacciones, especialmente complejas (Martínez Cañellas, 2004). Los intercambios internacionales llevan aparejados uno o varios contratos de compraventa, transporte, seguro, agencia, contratos bancarios especiales, relaciones con las Administraciones. La seguridad jurídica se ha buscado a diversos niveles (por sectores económicos, por regiones económicas, o en el ámbito mundial) y por medio de dos métodos: la creación 
del Derecho uniforme y la aparición de la autorregulación por parte de la misma comunidad de comerciantes internacionales. La desmaterialización de los títulos papel, las transferencias electrónicas de dinero, la titularización, la digitalización de documentos, los centros de outsourcing, los market place, las cadenas de suministro, los supermercados, el consumo masivo, la oferta de servicios o mercaderías por Internet, la multimedia y demás manifestaciones de la informática requieren regulaciones expeditas que confronten múltiples hechos y situaciones económico-sociales que se consolidarán según el ritmo en que sean asimilados los avances que denotan la economía y el comercio.

\section{MÉTODOS DE CREACIÓN DEL DERECHO COMERCIAL INTERNACIONAL A PARTIR DE LA GLOBALIZACIÓN}

Oportuno estudiar ahora los impactos de la Globalización en los sistemas jurídicos, advirtiendo que se trata de un proceso de gran velocidad no solo por los adelantos tecnológicos que se expanden con rapidez por el mundo sino por acontecimientos de gran resonancia, que, tal como se ha expuesto, ha trastocado el orden clásico de las fuentes del Derecho, lo que conlleva una ruptura del esquema clásico del Derecho nacional estatal de conformación piramidal, así como lo concibió Kelsen. Por tanto, el nuevo paradigma de las fuentes reclama la superación del modelo clásico, por lo que debe afrontarse con un nuevo método y una nueva mentalidad, conclusión que se considera acertada (Alegría, 2012).

La armonización del Derecho mercantil parte de la premisa de que es buena para el desarrollo de la economía mundial, aunque no todos están de acuerdo con esto, y puedan existir discrepancias por razones políticas, de soberanía nacional, entre otros. Sin embargo, la creación del nuevo orden económico mundial, y la tendencia unificadora del Derecho mercantil internacional, exige ser parte de estas nuevas normativas jurídicas que se desarrollan al margen de un Derecho nacional. La unificación es fruto del incremento del comercio internacional derivado de la masificación de la producción, que ha tenido origen en las economías de escala y ha sido empleada en mercados exteriores, accesibles gracias a las mejoras técnicas de los transportes y las comunicaciones. Con la actual Globalización, el comercio internacional deja de ser exclusivo de los grandes operadores especializados, para convertirse en algo cotidiano, accesible a medianas y pequeñas empresas (Martínez Cañellas, 2001).

Tanto en uno como en otro caso, es necesario un nuevo ordenamiento jurídico que dé seguridad a las transacciones, especialmente complejas. Ese es el sentir de Martínez Cañellas (2001):

Todo ello ha llevado a buscar un ordenamiento universal de estas operaciones, independiente de los países entre los que tengan lugar las mismas. No es una novedad histórica. Ya en la Edad Media el nacimiento de la Lex Mercatoria en Europa obedece a motivos similares. No obstante, el fenómeno de la Globalización ayudado por los medios técnicos que permiten un comercio electrónico transfronterizo, ha generado urgencia en la búsqueda de la unificación 
jurídica internacional. Esta se da en materias como la insolvencia transfronteriza, el comercio electrónico, los pagos internacionales, etc.; y se produce a diversos niveles: por sectores económicos, por regiones económicas, o en el ámbito mundial (p.9)

Se ha insistido en que el proceso de Globalización trae consigo una trasformación gradual no solo de la estructura y organización política estatal, sino también de los aparatos y mecanismos de producción normativa (Cortés, 2007). El nuevo orden mundial reclama un espacio significativo, que se ve expresado en los procesos de integración regional; sin embargo, ese batimiento de las fronteras nacionales, con la consecuente necesidad de producir normas que responda a los modernos proceso de Globalización, ha tenido consecuencias, también, sobre mecanismos de producción de normas dentro del territorio del Estado, en el ámbito tradicional de aplicación de la ley, pues ese incremento de libre tránsito de personas y mercaderías, sumado a la facilidad de procurarse una pronta información sobre lo que sucede más allá del propio confín, ha hecho que la circulación de creencias, ideas, ideologías, doctrinas, modelos, formas de ser, sea una constante, y que, por tanto, la noción y la existencia de la sociedad pluralista, verdadero signo distintivo del constitucionalismo moderno, se refuerce definitivamente, y se traduzca en la formación de centros alternativos de poder, grupos de personas, más o menos numerosas, que anticipan en cierta actividad o que predican ciertos valores, y que aspiran a la formación de un Derecho autorreferencial, en lo posible creado directamente por ellos, y que pretende reconocimiento en respeto y promoción, justamente, de esa sociedad pluralista a la que pertenecen.

Esta apertura de las fronteras y de las potestades estatales para dictar normas ha permitido a la sociedad mundial la configuración de nuevos regímenes que entran en conflicto con el positivismo tradicionalista del Estado; no obstante, cada vez más es un mecanismo aceptado por los miembros y operadores sobre todo el comercio, lo cual no quiere decir que se está gestando una inobservancia de la norma, sino que lo que se persigue es crear un sistema en el que paralelamente ambos puedan subsistir y nutrirse uno del otro, atendiendo las necesidad que engloba las sociedad de comerciantes tomando en cuenta la rapidez con que evolucionan sus transacciones. Entonces, sin duda, el problema es de fuentes del Derecho: la cuestión, en efecto, es sobre la producción normativa, esto es, la de saber quién está legitimado para producir Derecho y cómo se pueden y deben combinar todas esas normas de las más variada proveniencia.

Necesario retomar la pregunta que se hace Cortes (2007): ¿Dónde queda la seguridad jurídica cuando la ley del Estado comparte su ámbito de vigencia con normas de variada procedencia? Pero también se cuestiona: ¿Dónde encontrar la fijeza del Derecho cuando este se presenta, como una realidad individual o de grupo, pero no como realidad (necesariamente) social, una realidad, aquella individual, que rechaza el carácter absoluto de los valores y que, por el contrario, genera y alimenta disputas sobre la propia visión del mundo? Y, por último, ¿será necesario sacrificar la certeza para proteger el pluralismo y para garantizar el libre mercado? Se reitera que no siempre el Derecho positivo genera una certeza plena, sobre todo en el campo comercial, más aún en el plano internacional, 
cuando se enfrentan normas de distintos sistemas jurídicos, lo que permite dejar a merced del positivismo soluciones que no responden a una regulación local.

Y es que la regla central del positivismo es aquella según el cual el mandato debe ser dado antes del conflicto, pues su función, la de la ley, consiste en dar a los hombres la certeza del Derecho, es decir, en hacerles saber lo que deben hacer o no hacer, y a qué consecuencias se exponen haciendo o no haciendo. Es la idea de un Derecho abstracto, basado en nociones ideales y confiando en sus propósitos, a la inteligencia del legislador, pero, ¿qué acontece cuando el Derecho calla en el quehacer del comerciante?

Lo enunciado con antelación, y sin más rodeo doctrinario, lleva a la reafirmación de que el pluralismo (con sus numerosos canales de creación del Derecho) no puede ser reducido a meras estructuras legales, pues el Derecho, se dice, es un fenómeno que está profundamente calado en la realidad, de tal forma que al lado del Derecho estatuido existen hoy una serie de elementos y mecanismos capaces, por sí solos, de regular las relaciones jurídicas en la sociedad, sobre todo que no debe entenderse al Derecho únicamente desde la perspectiva de la ley dictada por un órgano estatal, esto que se dice hoy, también se entendía en la antigua Roma o en los antiguos grupos de mercaderes.

¿Cómo se configura este nuevo sistema de fuentes? Por supuesto que no resulta fácil romper esquemas tradicionalistas, lo cierto es que hoy en el Derecho se traducen los cambios sociales, políticos, económicos de los tiempos recientes, por lo que se ve obligado a responder sin tardanza a los retos que le plantea esa sociedad en permanente trasformación; de igual manera, así lo reclama la nueva realidad del Derecho mercantil en su expresión internacional, dado que se ha experimentado una incontenible expansión en la vida comercial contemporánea, por lo que quedan atrás leyes y códigos con visión nacionalista. Las sociedades mercantiles se difunden por los distintos países, montan filiales y subsidiarias, multiplican el volumen de sus negocios y quieren hacer presencia hasta en el último rincón del planeta. La fabricación y distribución de mercancía se realiza en cualquier parte del mundo y, por tanto, se quiere traficar sin distinción de nación (Ravassa Moreno, 2004), además de que los empresarios que actúan en todos los lugares de la tierra demandan libertad de establecimiento, para ellos y sus empresas, acceso a los mercados extranjeros, reglas básicas idénticas y principios generales comunes que orienten sus negocios y sus expectativas. La seguridad jurídica en la negociación, establecimiento y planificación frente al mercado es la garantía más preciosa que la iniciativa comercial puede pedir y de hecho demanda con todo rigor.

Así las cosas, el éxito que alcanza el pluralismo jurídico es resultado directo del diálogo entre las fuentes; por tanto, se debe concluir entonces que la certeza del Derecho es producto de la conjunción de todos los factores operantes en un determinado sistema jurídico. Esos varios factores o formantes concurren para el establecimiento de la regla aplicable, y si no hay armonía entre ellos (normas, Derecho aplicable, opinión de los juristas), será el momento de intensificar el debate a fin de encontrar un punto de confluencia (Cortes, 2007), verbigracia, el Derecho mercantil internacional ha encontrado su fluidez en la creación de normas uniformes, o en la armonización de normas jurídicas. Debe ser así porque el Derecho mercantil internacional tiene dos objetivos básicos que 
cumplir: la seguridad jurídica y el desarrollo (Ravassa Moreno, 2004). En el comercio internacional, las reglas de juego deben ser claras. Su aplicación a los casos concretos deberá ser uniforme, dado que la seguridad jurídica requiere un esfuerzo continuado de elaboración e integración de normas que puedan proyectarse sobre unas relaciones pacíficas de orden mercantil.

Históricamente, al término de la Segunda Guerra Mundial se liberalizó el comercio ${ }^{13}$ y como consecuencia de ello se intensifico el tráfico de bienes y servicios a escala global, por lo que se comenzó a tener más políticas económicas aperturistas; no se puede negar que la independencia y el nivel de intercambio económico internacional han crecido a pasos agigantados. El siglo XXI se caracteriza por el afianzamiento del libre mercado y del capitalismo, que ha obligado a examinar muchas instituciones y estructuras en lo económico, financiero, jurídico, entre otras, y en las que naturalmente se encuentran los contratos mercantiles, quizás el vehículo más importante de su negocio o actividad. De ahí que han surgido mecanismos jurídicos con un ropaje que potencialmente tiende

13 Hasta 1945, el comercio internacional se caracterizaba por una dimensión estatal de los poderes económicos privados, fuertemente apoyados por la política expansionista de los Estados de donde procedían. Por entonces, el número de dichos Estados era muy reducido: aquellos en donde la acumulación de capital en capital financiero, como consecuencia de la revolución industrial, habían propiciado una política de expansión internacional, a saber, Francia, Gran Bretaña, Estados Unidos. Pero a partir de 1945 fue menester la adopción de un orden normativo capaz de responder al reto de un cambio radical en las relaciones económicas internacionales. El régimen del comercio ya no respondía al esquema demoliberal de las economías estatales que en el plano internacional se traducía en tres principios básicos, los cuales, con mayor o menor intensidad, estuvieron presentes a lo largo de todo el pasado siglo en las disposiciones internas de los Estados y en la generalidad de los convenios de comercio. Se trata, en primer lugar, del principio de libertad de comercio, fiel reflejo del liberalismo económico proclamado por la Revolución francesa; en segundo término, del principio de libre cambio, vencedor del proteccionismo que había caracterizado el período anterior e indispensable para el desarrollo de las transacciones internacionales, y, por último, del principio de la igualdad de trato entre el extranjero y el nacional en materia mercantil. La nueva situación del comercio se proyectaba, por el contrario, a una escala universal como consecuencia obligada de los acontecimientos políticos, económicos y sociales surgidos en la postguerra. Baste retener la revolución tecnológica y demográfica, vinculada a los requerimientos de una política de desarrollo y de reconstrucción de un mundo gravemente damnificado tras la contienda. Se trataba de exigencias que al proyectarse en el plano internacional alteraron los planteamientos clásicos del capitalismo burgués y del nacionalismo estatal. Una nota característica de nuestro tiempo es la vocación de los Estados a relacionarse económicamente con el exterior, superando situaciones de autarquía económica. La historia ha probado los beneficios de las transacciones comerciales internacionales, que han permitido la especialización y, por ende, el aumento de la productividad con la subsiguiente mejora de las posibilidades de consumo. Precisamente esta especialización se consigue a través del comercio internacional, al permitir el desarrollo de las posibilidades de producción y de consumo que, sin su existencia, quedarían relegadas a lo producido en el entorno económico de la autarquía; sin la existencia de tal comercio no solo se limitaría el consumo de los Estados, sino que supondría una significativa reducción de los mercados y el freno del desarrollo tecnológico. Este fenómeno ofrece tres consecuencias de singular importancia: la interdependencia en el mercado de productos, con el consiguiente aumento de las exportaciones y de las importaciones; la interdependencia en el mercado de trabajo, con su secuela de desplazamientos de trabajadores y de profesionales a través de las fronteras, y la interdependencia en el mercado de capitales, que implica que el dinero puede invertirse a escala internacional allí donde genere mayores rendimientos (Fernández Rozas, 2000, p. 2). 
a sentar pautas expresadas en normas y principios de naturaleza internacional, con el fin de conservar igualdad en el equilibrio y no vulnerar los derechos y obligaciones de una u otra parte, como quiera que por lo general se involucren intereses de ciudadanos o corporaciones de distintos países (Peña Nossa, 2010); por tanto, la búsqueda de las relaciones jurídicas seguras y estables ha sido precisamente el motor sobre el cual ha girado el movimiento de unificación y armonización jurídica internacional de los contratos comerciales internacionales, motivada a su vez por los cambios tecnológicos, comerciales e industriales y por la Globalización que se ha producido en una gran parte de las economías del mundo (Perales Viscasillas, 2014).

Este proceso de liberalización del comercio mundial tiene dos efectos muy concretos sobre la estructura de la contratación internacional, según López Guzmán y Monge Mayorca (2007), a saber:

a) al haber fortificado el capital financiero transnacional, el Estado dejó de ser el epicentro del quehacer jurídico y por ende se marginó de los intercambios comerciales internacionales, y ahora son las empresas multinacionales y los grupos empresariales los principales actores del comercio exterior. Hoy, son ellos lo que diseñan nuevos tipos contractuales y nuevos métodos de solución de disputas internacionales ajenos al Derecho contractual codificado del Estado-Nación. Se trata de verdaderos instrumentos jurídicos-negociales que coadyuvan en el comercio de bienes y servicios a escala global, y que empiezan a reemplazar el clásico sistema de contratación soportado en rígidos esquemas jurídicos contenidos en leyes y códigos de Derecho privado. La liberación comercial requiere de contratos flexibles, atípicos y fundados en costumbres internacionales, y b) al solidificarse un conjunto de usos y prácticas en el comercio internacional, fue menester realizar un trabajo jurídico colectivo de armonización y unificación del Derecho contractual internacional, que ofreciera un alto grado de seguridad jurídica y que, además, tuviera legitimidad entre los operadores del comercio internacional, o, en otras palabras, que tuviera la suficiente fuerza vinculante en el tráfico mercantil internacional, como para que organismos internacionales, tribunales supranacionales o centros privados de arbitraje, se les atribuye la misma facultad de coerción jurisdiccional de que goza el Estado en su esfera interna (p. 22).

Para la génesis de este nuevo escenario político-económico-jurídico se debe saber que los procesos de armonización y unificación del Derecho mercantil internacional se han plantado como una nueva forma de hacer Derecho a manos de los operadores comerciales, entiéndase organismos, empresarios, el mismo Estado, entre otros, que además han tenido importantes repercusiones en los ámbitos social, cultural, histórico, lingüístico, ético e individual, de los que nacen tratados, convenciones, principios y demás. Los Estados que no han logrado integrarse en bloques económicos han decidido adoptar mecanismos de unificación o bien de armonización, por lo que es indispensable entender ambos procesos. 


\subsection{Unificación y armonización}

A pesar que no existan Estados integrados en bloque, tal como la Unión Europea, las políticas económicas invitan a relacionarse económicamente con el exterior, dado que la historia ha marcado los probados beneficios de las transacciones internacionales, que permiten la especialización y, por ende, el aumento de la productividad con la subsiguiente mejora de posibilidades de consumo; está de más decir el mejoramiento de la economía interna.

Precisamente esta especialización se consigue a través de los negocios trasfronterizos que facilitan el desarrollo de las posibilidades de consumo sin cuya existencia quedarían relegadas a lo producido en el entorno económico. Tal como compartieron López Guzmán y Monge Mayorca (2007), Fernández Rozas, Arenas García y De Miguel Asensio (2013) coinciden que el establecimiento del libre mercado trae consigo una reorientación de los procedimientos de producción jurídica y de la actividad de los poderes públicos que deben ahora ocuparse preferentemente de asegurar que la libre competencia en el mercado y que los servicios públicos administrados por empresas privados cumplan su cometido. Este nuevo contexto favorece la autorregulación o creación de normas sin la participación directa de los poderes públicos, lo que de manera insistente se ha referido aquí en torno al proceso de unificación o armonización, dado que surge como una alternativa para propiciar un equilibrio entre el Estado y el mercado. El mercado debe estar donde le corresponde y ser verdaderamente eficaz y productivo, pero el Estado no debe desentenderse de su protagonismo tradicional.

Entonces, ¿cómo llevar esto a una realidad jurídica? Esta interrogante reclama la necesidad de unificación y armonización, se basa en la comprobación de que las leyes nacionales suelen ser inadecuadas para los casos internacionales y de que existe una notable disparidad entre ellas.

Las labores de armonización y unificación del Derecho mercantil internacional describen el proceso mediante el cual se crean y aprueban normas o regímenes jurídicos destinados a facilitar el comercio internacional. Se determinan las esferas en las que el comercio internacional se ve obstaculizado por factores como la falta de previsibilidad en cuanto a la ley aplicable o la pervivencia de leyes obsoletas, difíciles de compaginar con la práctica comercial contemporánea. Gran parte de la doctrina que defiende estos procesos ve como un sueño a la Lex Mercatoria asociada a los usos y costumbres, para configurar nuevas de leyes y documentos técnicos -guías de aplicación- que permitan la adopción de los mismos por los congresos o parlamentos nacionales de los países, así como su aplicación en contratos internacionales, todo con el fin de abrir las puertas a los procesos unificadores y armonizadores (Peña Valenzuela, 2002).

Por otra parte, se considera propicio enunciar que la Comisión de Naciones Unidas para el Derecho Mercantil Internacional (CNUDMI o UNCITRAL, como corresponde a la sigla en inglés) ha entendido por armonización el proceso mediante el cual se tiende a facilitar la modificación de ciertos regímenes del Derecho interno de los Estados, para conferir previsibilidad a las operaciones comerciales transfronterizas, y unificación es 
el proceso por el cual los Estados aprueban normas o regímenes jurídicos comunes para regular determinados aspectos de las operaciones mercantiles internacionales.

Es importante destacar que en el caso de la unificación en sentido estricto decimos normalmente Derecho internacional uniforme, aunque en el caso de la armonización no se habla de Derecho internacional, porque cada Estado goza de una cierta discrecionalidad en la determinación del contenido y alcance de la norma que introduce en su Derecho internacional ${ }_{i}$ discrecionalidad que no se tiene en caso de que se trate de un Derecho uniforme de origen convencional. El objetivo de una armonización es propender al fortalecimiento de las similitudes de los derechos de diferentes países, pero no reclama su unificación. La armonización es un concepto bastante flexible e indeterminado.

Tomando en cuenta que el campo de aplicación del Derecho mercantil internacional es aquel que se encarga de regular las distintas relaciones jurídicas internacionales que se desarrollan con ocasión de las distintas operaciones mercantiles, esto es, los actos y contratos que se celebran entre los diversos participantes del mercado, la actividad mercantil internacional adquiere valor jurídico a través de diferentes medios, como la codificación del Derecho mercantil, el surgimiento de la legislación supranacional, las leyes modelos, los usos y costumbres, los códigos de conducta y los mismos contratos. En esta labor de unificación y armonización del Derecho mercantil internacional han contribuido de manera constante los Estados, buscando eliminar los obstáculos jurídicos que se presentan en el comercio internacional (Peña Nossa, 2010). En esto encontramos materializada la nueva tendencia de flexibilidad de fuentes del Derecho siendo que su naturaleza jurídica no se obtiene de una sola fuente, es decir, la naturaleza jurídica de la contratación mercantil internacional resulta en muchas ocasiones de los procesos de armonización y unificación.

A manera de conclusión, pertinente acudir a los argumentos de Ruiz Pinzón (2012), teniendo entonces que en el caso de la armonización no se habla Derecho internacional armonizado, porque cada Estado goza de una cierta discrecionalidad en la determinación del contenido y alcance de la norma que introduce en su Derecho interno; discrecionalidad que no se tiene en caso de que se trate de un Derecho uniforme de origen convencional, que tiene como propósitos la reducción del riesgo legal, el mejoramiento de las leyes locales que afectan el comercio internacional y el mejoramiento en las cualidades profesionales de los agentes del comercio internacional y de sus intermediarios y asesores.

Ambos procesos pueden resultar adecuados para la realidad del comercio internacional, sobre todo cuando se trata de buscar una alternativa a la realidad de la normativa estatal, sin embargo, se considera que la faceta de la unificación que aquí se abordó constituye la garantía óptima de la continuidad de las relaciones jurídicas a través de espacios supranacionales, dotándolas de mayor seguridad jurídica y facilitando al operador jurídico la previsibilidad del Derecho. El propósito de la uniformidad en las relaciones comerciales internacionales consistente en ofrecer una mayor certeza jurídica a las partes en la contratación, para lo cual las normas aplicables deberán haber sido elaboradas a partir de criterios de objetividad y de equidad. La unificación y la creación del Derecho en el plano transnacional no es otra cosa que expresión de la realidad comercial en la actual 
etapa de las transacciones mercantiles internacionales, tal como lo expresan Fernández Rozas, Arenas García y De Miguel Asensio (2013); no obstante, se considera oportuno conocer cuáles son los mecanismos por los cuales despliegan su alcance ambos métodos para posteriormente determinar sus ventajas, desventajas e importancia para su aplicación material.

\subsection{Herramientas para la armonización y unificación del Derecho comercial internacional}

En primer orden, todas las relaciones económicas que se han intensificado por la reducción de barreras para el tráfico internacional de bienes y servicios, además de otros factores, entre otros, la facilidad de comunicación entre los operarios del mundo de los negocios producto del desarrollo de las nuevas tecnologías, la evolución de los modernos medios de transporte, han producido como efecto en el mundo jurídico, la necesidad de reducir las diferencias que separan a los diferentes sistemas, en aras de brindar seguridad jurídica a las transacciones de bienes y servicios (Oviedo Albán, 2003).

Existen distintos modos de unificar o armonizar el Derecho mercantil internacional; no obstante, resulta menos complejo determinar los mecanismos que llevan a una uniformidad. Y es que, de la lectura de las líneas anteriores, se colige que las convenciones, tratados o cualquier documento de carácter internacional que se introduzca al Derecho nacional según los procedimientos de incorporación de instrumentos internacionales de

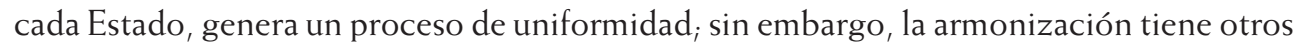
mecanismos que, según su aplicación, puede considerarse como propia de este proceso.

La unificación internacional del Derecho contractual no tiene un mecanismo único, y no es ajeno tal proceso a dificultades de diverso orden. El primer mecanismo es de carácter convencional, la coexistencia y diversidad de varias leyes que dentro de ellas se encuentran fuentes como los tratados multilaterales que buscan la unificación de las reglas de conflicto, y los tratados multilaterales que tienen por objeto la unificación de las reglas de fondo; en segundo lugar, se sitúa el Derecho fruto de la labor emprendida por instituciones como la Comisión de Naciones Unidas para el Derecho mercantil internacional (CNUDMI o UNCITRAL, como corresponde a la sigla en inglés), el Instituto para la Unificación del Derecho Privado (UNIDROIT, por sus siglas en francés) y la Cámara de Comercio Internacional de París (CCI), y, en tercer lugar, la unificación del Derecho contractual puede provenir del Derecho comunitario, originado en el surgimiento de organizaciones económicas, dictado por los organismos facultados para tal efecto. En el caso europeo, dicha unificación se da a través de los reglamentos, directivas, y decisiones (Oviedo Albán, 2003).

Marín López (1969) sugiere unos mecanismos para la unificación más detallados: a) las leyes nacionales uniformes, b) los convenios internacionales y c) la unificación de las prácticas del comercio internacional, especialmente la fijación de cláusulas contractuales tipo y de condiciones generales de venta, esto relacionado con el desarrollo de la costumbre y el arbitraje comercial internacional. Pues Marín López (1969) y Oviedo 
Albán (2003) manifiestan que la unificación del Derecho mercantil internacional no se ha hecho hasta ahora de una forma ordenada y sistemática, sino a medida que las necesidades lo exijan. Tampoco se ha empleado un método universal, sino que la mayoría de las realizaciones es de tipo regional.

\subsection{Virtudes y falencias de la armonización y unificación del Derecho comercial internacional}

Los procesos de unificación o armonización han recibido tradicionalmente una valoración positiva. Hay que tener en cuenta que con ellos lo que se pretende es que los Estados compartan unas mismas normas sustantivas o de fondo para regir las operaciones internacionales, en algunos casos incluso para regir también las operaciones internas, y evitar así los inconvenientes asociados a la norma de conflicto ; sin embargo, como dice Campuzano (2003), el problema es que la experiencia que existe hasta la fecha en materia de unificación material no permite ser muy optimistas. La elaboración de convenios suele estar plagada de dificultades, imponiéndose en muchos casos una limitación de objetivos o soluciones de compromiso.

Por lo anteriormente referido, antes de hablar de ventajas o desventajas, se resalta que los procesos de unificación y armonización presentan una serie de dificultades de diverso orden que impiden la estructuración y consolidación del Derecho mercantil internacional como categoría sistemática. Oviedo Albán (2003) encuentra que estas dificultades pueden ser de tipo histórico, económico, jurídico y teórico, pero sobre todo se pueden visualizar cuando los Estados no son partidarios en muchas ocasiones de ceder soberanía a legislaciones foráneas; en este mismo sentido se expresa Martínez Cañellas (2004), dado que manifiesta que los detractores de la unificación basan sus críticas en la transferencia de soberanía nacional, toda vez que supone por parte de los Estados la pérdida de autonomía.

Sacco (2006) enuncia por su parte que el proceso de unificación puede ser peligroso porque una convención o tratado debidamente incorporado al Derecho nacional tiende nuevamente a una fuente del Derecho impuesta por la ley, y es que el autor defiende la idea, en el caso de la contratación internacional, que en la medida en que la fuente de Derecho sea la voluntad de los interesados (usos comerciales, clausulas sugeridas por las cámaras de comercios), no existirá una ruptura traumática por el Derecho preexistente. Un código o una ley no tienen la misma flexibilidad, si el código que es nacional refleja la opinión de juristas del país y su lenguaje, lleva a la jurisprudencia reciente, enraizada en la práctica local, a abrir posibles soluciones que han incoado demandas sociales conocidas y difundidas en el país; no tiene nada de impredecible.

Por su parte, Martínez Cañellas (2004) agrega que el Derecho mercantil internacional, en su faceta unificadora y armonizadora, plantea problemas que surgen de la necesaria adaptación de los sistemas jurídicos estatales, pertenecientes a diferentes familias jurídicas, a un nuevo sistema jurídico común; la faceta uniformadora y armonizadoras encara buenas críticas sobre sus bondades por ser esta un instrumento de la doctrina neoliberal, 
sin distinguir si tal unificación o armonización es de Derecho privado o de Derecho público. Esta falta de distinción parece adecuada si se parte del hecho de que en muchos contratos internacionales las partes que contratan tienen un poder negociador diferente. En el comercio internacional se sitúa a empresas pertenecientes a países desarrollados, con larga experiencia en comercio internacional y medios técnicos y financieros para desarrollarla, junto con empresas de países en vías de desarrollo, como de Asia, África y Latinoamérica, carentes de dichos servicios, y que aparecen como la parte débil del contrato. La protección de esta parte débil procede tanto del Derecho público nacional (orden público interno, normas imperativas), como internacional (en el seno de la Organización Mundial del Comercio), como del Derecho privado (en la elaboración de usos y normas uniformes que busquen el equilibrio de las partes).

Es necesario además comprender que los modelos aperturistas de mercado, o las teorías que avalan el libre comercio, traen consecuencias directas al Derecho mercantil: la internacionalidad que define sus características demanda espacio en los procesos unificadores o armonizadores, que buscan alejarse de la misma ampliación de normas de Derecho internacional privado que normalmente buscan nacionalizar la solución de un conflicto internacional aplicando indirectamente la norma nacional, habida cuenta de que el Derecho Internacional Privado y su sistema conflictual se revelaban insuficientes para cubrir el amplio elenco de cuestiones que producían los contratos mercantiles.

Para entender los alegatos anteriores, es necesario enunciar que el Derecho internacional privado está constituido por normas internas, tratados de Derecho internacional, costumbres, que, mediante la identificación de un componente internacional dentro de una determinada relación jurídica, sugiere qué ley nacional será la aplicable (Oviedo Albán, 2004). Así lo expresa Alcover Garau (1991): "En una primera aproximación el que un contrato sea internacional significa que en él confluyen elementos de diversos Estados, los que determinan la necesidad de acudir a las normas de conflicto que ofrece el Derecho Internacional Privado a fin de fijar el régimen jurídico aplicable" (p. 42). De ahí que para muchos el Derecho internacional privado no sea más que un Derecho que soluciona conflicto de leyes, pero no regula, en sí mismo, la relación jurídica concreta.

En el hecho que se acaba de señalar, se origina la crítica que al mismo se le hace. A esta deficiencia del sistema conflictual se une el inconveniente de que los códigos de los distintos ordenamientos internacionales, al ser mucho de ellos del siglo pasado, no solo adolecen de graves lagunas sino que además son instrumentos inadecuados para regular la moderna contratación internacional, pues muchos de los códigos aún vigentes parten de una realidad preindustrial anclada en los tipos contractuales tradicionales que no pudieron prever los cambios tecnológicos industriales y comerciales hoy imperantes (Gómez Segade y García Vidal, 2010); por ende, básicamente consiste en afirmar que, al ser los códigos nacionales los que resultan aplicables a las transacciones internacionales, son estas soluciones que no obedecen a la naturaleza de las mismas, y el porqué se abogue por la configuración de un Derecho propio del comercio internacional; a esto se llega mediante la unificación o la armonización, lo que resulta ventajoso para las contrataciones internacionales. El fenómeno globalizador ha llevado a pensar en contar con 
una seria de reglas que, a diferencia del Derecho internacional privado, buscan alcanzar una regulación uniforme.

Para dar más claridad a estas últimas aseveraciones, es válido apoyarse en un argumento dado por Bonilla Aldana (2013), dado que, en efecto, gran parte de las transacciones comerciales que se producen en el mundo no tienen un carácter local. Por el contrario, son transacciones en las que es frecuente la participación de agentes de diferentes países que desarrollan su relación en distintos territorios y en consecuencia podrían estar sometidos a la ley de cualquiera de ellos. En este sentido, una relación de comercio internacional puede estar sometida a diversos ordenamientos que se encarguen de regular los distintos aspectos de la relación comercial, lo que genera un alto grado de incertidumbre para las partes que desconocerán la regulación que rige el vínculo contractual. Es así que, a manera ejemplo, un contrato de compraventa internacional de mercaderías celebrado entre dos agentes, cuyos establecimientos se encuentran en países distintos, puede establecer que las mercaderías sean entregadas en un territorio diferente a aquel en el cual fueron manufacturadas o fabricadas. Puede haberse pactado, adicionalmente, que el pago por dichas mercaderías se produjera en otro Estado distinto al de las partes y al del lugar de entrega de los productos.

¿Cómo se resuelve esta telaraña jurídica? Primeramente, debe cuestionarse sobre cuál de estas regulaciones sería la que regiría el vínculo contractual, pues tal y como se encuentra planteado el ejemplo, al menos cuatro ordenamientos podrían regir la relación de comercio internacional. Adicionalmente, en caso de conflicto, cada uno de los ordenamientos puede proporcionar diversas soluciones a la problemática planteada, sometiendo la relación a un alto grado de incertidumbre como consecuencia del desconocimiento del régimen aplicable $y$, por tanto, la gran problemática que se presenta en este caso es el de la ley aplicable a la relación contractual, no solamente en caso de conflicto, sino en general en cada una de las etapas de la relación comercial. Problemática que es de una gran importancia si se tiene cuenta que dicha incertidumbre constituye un factor que no solo genera un aumento en los costos de transacción, sino que también produce una fuerte barrera para el establecimiento de relaciones comerciales y para el ingreso de nuevos agentes y productos al mercado.

Muy probablemente, aunque no sea la vía indicada, la solución a este cuestionamiento se sitúa en las tradicionales normas de conflicto impuestas por el Derecho internacional privado. Sin embargo, estas leyes, para Goldring, citado por Bonilla Aldana (2013), "aunque fascinan a los abogados, irritan a los comerciantes por el costo, retraso e incertidumbre que traen consigo" (p. 83), ellas (normas de conflicto) no proporcionan una solución acorde con la rapidez de las transacciones ni otorgan certeza en cuanto al régimen legal aplicable a la relación contractual, ya que, como ninguna otra normatividad, estas difieren de un ordenamiento a otro. Como respuesta a lo anterior surgió en la comunidad internacional la necesidad de crear disposiciones armónicas y unificadoras que disminuyeran las divergencias entre los distintos ordenamientos, eliminaran la incertidumbre en cuanto a la ley aplicable y redujeran los costos de transacción. 
La dicotomía entre lo local y lo global, definitivamente, ha puesto en jaque a los Estados-Naciones, en una situación problemática, evidentemente, en el nuevo escenario global es solo un ente local más, por lo que se dice que el traslado de la potestad exclusiva de dictar Derecho a instancias privadas, como corporaciones, que desembocan en la elaboración de códigos de conducta (generalmente criterios técnicos de homologación de productos) a los cuales debe conectarse con la reconsideración del sistema tradicional de fuentes (Sanz Burgos, 2003). Esta reconfiguración del sistema de fuentes se enmarca en toda una revolución de los modos de gobernar, que (a causa del crecimiento de la complejidad de los factores a tener en cuenta a la hora de dictar una norma) ya no puede llevarse a cabo simplemente mediante órdenes, sino a través de técnicas de fomento de la actividad autónoma y del compromiso entre intereses encontrados.

Oportuno señalar además que las transacciones internacionales presentan siempre una complejidad, habida cuenta de la variedad de ordenamientos jurídicos que pueden regirlas. Para aminorar, entonces, estas complejidades, se tienen los mecanismos uniformadores y/o armonizadores del Derecho; sin embargo, se enfatiza en el contrato de compraventa internacional de mercaderías, al cual el Derecho uniforme internacional le ha puesto una especial atención. Pues bien, la misma complejidad que ofrece la relación contractual produce graves dificultades para determinar el régimen jurídico aplicable: la circunstancia de que los diversos elementos estructurales y dinámicos del contrato puedan estar sometidos a varios ordenamientos puede quebrar la armonía que debe presidir las obligaciones de las partes, y, sobre todo, los distintos ordenamientos nacionales, y en especial los continentales, que conforman el Derecho comparado y a los que se remite la norma de conflicto son insuficientes para regular la moderna contratación internacional, ya que contienen un ordenamiento jurídico de los singulares contratos especiales que adolecen de una visión superada o, para emplear una expresión que ha hecho fortuna, idílica, al buen parecer de Alcover Garau (1991).

Verdaderamente, el comercio es ante todo y por su propia naturaleza compraventa, concepto que comparte Boyeras Schumann (2013): "Hoy, los intercambios comerciales de exportación e importación entre los estados se articulan normalmente mediante el contrato de compraventa, cuya causa es el intercambio de cosa por dinero" (p. 2). Los aportes de Vázquez Lepinette (1995) ayudan a seguir configurando la realidad de la unificación y la armonización del Derecho, específicamente para el contrato de compraventa internacional de mercaderías, contrato básico del tráfico en una economía que ha superado la etapa de trueque o de la permuta y que instaurado el dinero como medio de cambio, siendo el instrumento jurídico y económico más idóneo y frecuente para la circulación de bienes desde sus productores a sus consumidores. Por estas razones, son múltiples las causas que subyacen al fenómeno de la unificación legislativa en materia de compraventa, pero en síntesis se pueden señalar básicamente tres órdenes de factores: unos de carácter comercial, otros de naturaleza estrictamente técnico-jurídica y otros de carácter político.

Es un deseo generalizado de todos los Estados el fomento del comercio internacional, a pesar de que su regulación se enfrente al positivismo jurídico, por los efectos 
beneficiosos que tiene sobre la economía nacional una de las formas de fomento. Es, como dice Bonell, citado Vázquez Lepinette (1995), por crear normas cuyo contenido se adopte mejor a las exigencias planteadas por la realidad del comercio internacional, y que además permitan disminuir los costes de la incertidumbre que se deriva de la falta de un marco jurídico adecuado en el comercio internacional que hace que, pese a su frecuencia, la compraventa internacional construya una operación compleja y, por lo tanto, relativamente arriesgada. Es decir, la unificación del Derecho de la compraventa internacional pretende dar respuesta a dos condiciones que todo empresario considera esencial para el correcto desempeño de su actividad, como son la existencia de un Derecho adaptado a sus necesidades y la certeza en la aplicación del mismo, máxime si se tiene en cuenta que, en la inmensa mayoría de los casos, la compraventa internacional se inserta en un marco contractual más complejo.

En estos replanteamientos de una realidad jurídica internacional en temas de compraventa internacional de mercaderías, se insertan perfectamente la unificación del Derecho mercantil internacional. A manera de conclusión, es oportuno citar las palabras de Seco Caro (2009) y Pardo (2011), quienes insisten en que la necesidad de la unificación legislativa respecto al contrato de compraventa fue, pues, sentida universalmente, y según evolucionan los negocios internacionales, siguen sintiéndose. El Derecho mercantil internacional está en plena capacidad de generar en los sistemas de Derechos nacionales procesos de armonización y unificación, en su mayor parte, como producto de instituciones especializadas, como las que se mencionaron líneas arriba. En palabras de Pereznieto Castro (2013), de lo que se trata hoy en día es no de disminuir sino de desaparecer las diferencias entre los diversos sistemas, bajo la tesis moderna, que no atiende a sentimientos políticos o de defensa, sino simplemente a la constatación de la diferencia entre sistemas jurídicos internos y el internacional y, de ahí, rescatar los vínculos entre esos dos Derechos, que les permitan funcionar coordinadamente en beneficio del tráfico jurídico internacional, principalmente sobre el concepto de uniformidad y armonización.

\section{CONCLUSIONES}

$\mathrm{Al}$ tenor de un mundo globalizado, es preciso tornar la mirada a aquellos aspectos que influyen de manera directa al ser humano. Entre muchos otros, nos encontramos con el Derecho, esa ciencia que regula de antaño los quehaceres del hombre en sociedad, así como los ámbitos de cada una de las notas relevantes que producen efectos individuales y colectivos.

Efectivamente, se habla de una Globalización jurídica, un desarrollo del Derecho con efectos tanto internos como externos para los Estados, esa parcela jurídica que reclama soberanía dentro de sus fronteras, ese espacio terrestre y marítimo donde alcanza la aplicación de la norma imperativa nacional. Sin embargo, hoy en día la concepción tradicionalista del Derecho estatal está mutando, se transforma a pasos agigantados, y culpa de ello es la mentada Globalización. Fenómeno que, en ciertos casos, ha sido aplau- 
dido y en otros, desbastados, lo cierto es que para el Derecho comercial internacional ha generado más beneficios que desventajas.

El comercio, una de las actividades más longevas del ser humano, se ha desarrollado en gran medida durante este último siglo, en la medida en que las fronteras han dejado de ser un problema para el tráfico de bienes, se han expandido las vías terrestres y marítimas que permiten mejorar los recursos de transporte con el único fin de llevar las mercancías de un extremo a otro con el menor costo posible. Sin lugar a duda, los beneficiarios directos son los comerciantes, pero también la económica mundial y nacional; es indiscutible que los índices de crecimiento económicos están directamente ligados al crecimiento del comercio tanto nacional como internacional; de hecho, las políticas estatales tienden a favorecer las importaciones y exportaciones con aras de elevar sus índices económicos.

En este plano, el fenómeno globalizador ha impactado de manera directa en las nuevas formas de regular el comercio internacional, siendo que en muchas ocasiones las legislaciones nacionales por su rigidez y estaticidad no son acordes con las necesidades de los comerciantes. Es aquí donde han jugado un papel preponderante los actores del comercio internacional, quienes dan vida a través de la unificación y la armonización a instrumentos que regulen su diario quehacer comercial en el espacio internacional. En otras palabras, el panorama internacional actual que regula el negocio jurídico de la compraventa de mercancías ha evolucionado según las necesidades del gremio, amparado en los crecientes flujos de intercambios de bienes, y que, a su vez, se valen de las nuevas interrelaciones económicas y tecnológicas que existen entre las diversas regiones del globo. Con esto demostramos que la atención internacional sobre la regulación de la compraventa de mercaderías es amplia, tanto por sectores económicamente fuertes como otros que no tanto, dado que el flujo comercial, en palabras sencillas, permite un beneficio indiscutible para las economías.

La Globalización, de igual manera, ha impactado en el campo tecnológico, permitiendo una mayor fluidez en las contrataciones a distancia. Es entonces que cada día va en aumento el nivel de intercambio de bienes y servicios, tomando en cuenta las facilidades para contratar; los espacios comerciales son más reducidos, se crea una comunidad internacional con mayor dinamismo a raíz de una apertura comercial por medios tecnológicos. Así que se han creado diversos instrumentos internacionales que amparan la actividad económica comercial, como tratados, convenios, convenciones, etc.; sin embargo, en muchas ocasiones estos instrumentos encuentran limitantes dentro de las soberanías estatales, debido a que el Estado aún guarda una concepción tradicionalista en la forma de crear el Derecho, especialmente en los países de sistema de Derecho continental, cuya fuente principal y formal es la ley y, por ende, la apertura a estos nuevos métodos sería, según los Estados, una pérdida de esta potestad legítima: crear Derecho.

Como observamos a lo largo del desarrollo de este artículo, hoy por hoy, el comercio internacional abandona esta concepción tradicionalista, y es que desde el siglo XII, los comerciantes crean su propio Derecho; por tanto, el fenómeno globalizador ha pretendido recapitular esta parte de la historia tomando como parámetro el alto índice del comercio 
trasfronterizo. Por las razones expuestas anteriormente, los Estados que pretenden unirse a una armonización o unificación del Derecho comercial internacional, están vinculados con las eliminaciones de restricciones del comercio de cara a un fortalecimiento de sus economías. Y es que el Derecho no es ajeno a los cambios que demanda la sociedad, y en este caso específico, una sociedad de comerciantes globalizada; en consecuencia, los Estados como garantes de la producción de normas jurídicas deben armonizar y unificar las legislaciones para consagrar una apertura comercial. Deben también coincidir con la creación y existencia de nuevos ordenamientos jurídicos paralelos que han nacido de los manos de los actores internacionales con el único fin de crear un Derecho global del comercio internacional, el que no pretende despojar al ya conocido Derecho estatal.

\section{REFERENCIAS}

Alcover Garau, G. (1991). La transmisión del riesgo en la compraventa mercantil.: Derecho español e internacional. Madrid: Civitas.

Alegría, H. (2012). Globalización y Derecho. Revista Pensar en Derecho, 187, 267-284.

Alonso Soto, R. (2001). Competencia y comercio. El marco general. En I. Blásquez Navarro, C.; Esposito Maccissi y A. Remiro Brotons (Eds.), La Organización Mundial del Comercio y el regionalismo europeo. Madrid: Dykinson.

Aramburo Calle, M.A. (2013). Los límites de la justicia transnacional: el caso del Comercio Justo. En G.A. Ramírez Cleves, E.M. Marín Aranguren (Eds.), Comercio justo, Globalización y medio ambiente. Bogotá: Universidad Externado de Colombia.

Arévalo Mutiz, P. L. (2008). Los desafíos del Derecho frente a la Globalización. Revista Vía Iuris, (4), 75-93.

Bonilla Aldana, J. M. (2013). La armonización del Derecho, concepto y críticas en cuanto a su implementación. Revista e-Mercatoria, 12 (2), 80-139.

Boyeras Schumann, D (2013). La Compraventa Internacional de Mercaderías la modalidad FOB (Tesis inédita de Doctorado). Universidad Autónoma de Barcelona, España.

Campuzano, B. (2003). El Derecho contractual europeo. En, A.L. Calvo-Caravaca y P. Blanco Morales-Limones, Globalización y Derecho (pp. 73-85). Madrid: Colex.

Carbonell Sánchez, M. (2003). Globalización y Derecho siete tesis. Derecho PUCP: Revista de La Facultad de Derecho, (56), 157-173.

Carrascosa González, J. (2004). Globalización y Derecho Internacional Privado en el siglo XXI. Anales Del Derecho, (22), 17-58.

Castrillón y Luna, V. M. (2011). Derecho Mercantil Internacional. México: Porrúa.

Clerc, C. (2013). El Derecho Internacional Privado y los procesos globalizadores. Revista Prolegómenos. Derechos y Valores, 32 (16), 15-30.

Cortés, E. (2007). La Globalización como proceso: herramientas para pensar en procesos. En G.A. Ramírez Cleves, G. A., (Ed.), El Derecho en el contexto de la Globalización. Bogotá: Universidad Externado de Colombia.

Dávalos Torres, M. S. (2010). Manual de introducción al Derecho mercantil. Colección Cultura Jurídica. México: Nostra Ediciones. 
De Souza Santos, B. (1998). La Globalización del Derecho: los nuevos caminos de la regulación y la emancipación. Bogotá: Universidad Nacional de Colombia.

Domingo Osle, R. (2005). Gayo, Vattel y el nuevo paradigma jurídico global. En J.P. Pampillo Baliño y R. D. Rabinovich-Berkman (Coord.), Derecho supranacional, Globalización e integración jurídica (pp. 31-84). Buenos Aires: La Ley.

Farina, J. M. (2005). Contratos comerciales modernos: modalidades de contratación empresaria (3ra ed.). Buenos Aires: Editorial Astrea.

Fariñas Dulce, M.J. (2008). De la Globalización económica a la Globalización del Derecho: los nuevos escenarios jurídicos. Derechos y Libertades: Revista Del Instituto Bartolomé de Las Casas, (8), 179-194.

Fernández Rozas, J. C. (1996). Derecho del comercio internacional. Madrid: Eurolex.

Fernández Rozas, J. C. (2000). El Derecho del comercio internacional en el contorno de la Globalización. Revista del Colegio de Notarios del Estado de México, (5), 161-230.

Fernández Rozas, J. C.; Arenas García, R., y De Miguel Asensio, P. (2013). Derecho de los negocios internacionales (4ta ed.). Madrid: Iustel.

Flores Enciso, L.B. (2006). Los retos de un mundo Global. En Carlos Julio Pineda (comp.). Debates sobre Globalización y Derecho (pp. 33-44). Bogotá: Editorial Politécnico Gran colombiano.

García Flores, E. (2013). Globalización y Derecho internacional en la primera década del siglo XXI. México: Universidad Nacional Autónoma.

Gómez Segade, J. A. y García Vidal, A. (2010). El Derecho mercantil en el umbral del siglo XXI : libro bomenaje al Prof. Dr. Carlos Fernández-Nóvoa con motivo de su octogésimo. Madrid: Marcial Pons.

Grün, E. (2003). La Globalización del Derecho y los nuevos sistemas jurídicos del mundo globalizados: Fenómenos sistémicos y cibernéticos. Revista Jurídica Pielagus, (2), 7-18.

Jerez Riesco, J. L. (2007). Comercio Internacional (3ra ed.). Madrid: ESIC Editorial.

Jiménez Benítez, W. G. (2011). Globalización del Derecho. Aspectos jurídicos y derechos humanos. Nova et Vétera, 20 (64), 17-28.

López Daza, G. A. (2003). Globalización del Derecho y sistema Jurídico colombiano. Revista Jurídica Piélagus., (2), 19-28.

López Guzmán, F. (2003). Principios constitucionales de Derecho comercial. Bogotá: Ediciones Doctrina y Ley.

López Guzmán, F. (2011). Derecho comercial en la era de la Globalización. Bogotá: Ediciones Doctrina y Ley. López Guzmán, F. y Monge Mayorca, D.F. (2007). Tendencia a la Armonización y unificación del Derecho contractual en la era de la Globalización. En Fabián López Guzmán (Dir.), Derecho comercial y societario (pp. 1-63). Bogotá: Librería Ediciones del Profesional.

Marín López, A. (1969). Unificación del Derecho Mercantil Internacional. Revista Española de Derecho Internacional, 22 (1), 131-151.

Martí Borbolla L.F. (2005). Globalización y economía de Mercado Global. En J.P. Pampillo Baliño y R. D. Rabinovich-Berkman (Coord.), Derecho supranacional, Globalización e integración jurídica (pp. $31-84)$. Buenos Aires: La Ley.

Martínez Cañellas, A. (2001). El incumplimiento esencial en el contrato de compraventa internacional de mercaderías (Tesis inédita de Doctorado). Palma de Mallorca, Universitat de les Illes Balears. 
Martínez Cañellas, A. (2004). La interpretación y la integración de la Convención de Viena sobre Compraventa Internacional de Mercancías. Granada: Editorial Comares S.L.

Marzorati, O. J. (2003). Derecho de los negocios internacionales. Buenos Aires: Editorial Astrea.

Narváez García, J. I. (1995). Introducción al Derecho mercantil. Bogotá: Doctrina y Ley.

Ortega, M.; Londoño, M.; Peña Valenzuela, D.; Barquero Herrera, M.; Reyes Villamizar, F. y Cortés Ballén, D. R. (2008). Globalización y Derecho mercantil. Medellín: Cámara de Comercio de Medellín para Antioquia.

Oviedo Albán, J. (1999). Los usos y costumbres en el Derecho privado contemporáneo. Recuperado de http:// www.derecho-comercial.com/Doctrina/oviedo01.pdf

Oviedo Albán, J. (2003). Instituciones jurídicas en procesos de integración y Globalización: la formación del contrato de compraventa internacional de mercaderías. Vniversitas, (105), 463-552.

Oviedo Albán, J. (2004). Estudios de contratación internacional (régimen uniforme e internacional privado). Bogotá: Pontificia Universidad Javeriana.

Pardo, G. O. (2011). El contrato en el contexto de la unificación del Derecho privado. Anales Del Derecho, (29), 115-160.

Peña Nossa, L. (2010). Contratos mercantiles nacionales e internacionales. Bogotá: Temis.

Peña Valenzuela, D. (2002). Contratación Electrónica ¿Es necesaria una Convención internacional? Revista E-Mercatoria, 1(2), 1-17.

Perales Viscasillas, P. (2014). Derecho comercial internacional. Bogotá: Temis.

Pereznieto Castro, L. (2013). La revolución del Derecho Internacional Privado en el mundo de hoy. Anuario Hispano-Luso-Americano de Derecho internacional, (21), 401-419.

Ravassa Moreno, G. J. (2004). Derecho Mercantil Internacional: principios y normas. Bogotá: Ediciones Doctrina y Ley.

Restrepo Uribe, E. (2003). Comercio y Capitales Internacionales. En G. Zafra Roldán y C. J. Pineda (comps.), Globalización y Derecho (pp. 31-46). Bogotá: Fundación Politécnico Grancolombiano.

Rodríguez Fernández, M. (2016). Introducción al Derecho comercial internacional. Bogotá: Universidad Externado de Colombia.

Rodríguez Fernández, M.; Bonilla, F. A. y Franco Zárate Javier (2007). Revista E-Mercatoria, 6 (2), 1-58.

Romero Erazo, J. (1998). La contratación internacional en un mundo globalizado en permanente evolución. En German Jaramillo Rojas y César Torrente Bayona, Negocios internacionales: tendencias, contratos e instrumentos (pp. 25-34). Bogotá: Cámara de Comercio de Bogotá.

Ruiz Pinzón, C. A. (2012). Armonización del Derecho comercial internacional en las relaciones económicas exteriores de Colombia. Revista In Vestigium, 5, 117-125.

Sacco, R. (2006). Elogio a la uniformización del Derecho. Elogio a la diversidad en el Derecho. En L. Vogel (Dir.), Derecho global: unificar el Derecho: ¿Un sueño imposible? (pp. 13-29). Neiva-Huila: Editorial Universidad Sur colombiana.

Sánchez Torrez, C.A. (2011). Fuentes del Derecho en la Globalización. En J. González Ibáñez y E. García López, La crisis de las fuentes del Derecho en la Globalización (pp. 33-43). Medellín: Biblioteca Jurídica Diké.

Sanz Burgos, R. (2003). Notas sobre el Derecho y el Estado en la era de la Globalización. Boletín de La Facultad de Derecho, (22), 57-82.

Seco Caro, E. (2009). El contrato mercantil de compraventa. Madrid: Marcial Pons. 
Torres Manzo, C. (1961). Comentarios alrededor de dos preguntas sobre Comercio Internacional. Investigación Económica, 21 (83), 475-765.

Twining, W. L.; Guardiola Rivera, O. y Sandoval Villalba, C. (2003). Derecho y Globalización. Bogotá: Siglo del Hombre Editores.

Vásquez Vásquez, F. J. (2009). Impacto de la Globalización en el mundo jurídico. Opinión Jurídica, $8(15), 17-28$.

Vázquez Lepinette, T. (1995). La obligación de conservación en la Convención de Viena de 11 de abril de 1980 sobre compraventa internacional de mercaderías. Valencia: Tirant lo Blanch.

Vengoa, H. F. (2002). La Globalización: ¿un concepto elusivo? Historia Crítica, (23), 91-114.

Vieira Posada, E. (2011). Interpretaciones y transformaciones tecnológicas en los procesos de Globalización. Papel Político, 16 (2), 667-669.

Zapata de Arbeláez, A. (2003). La internacionalización del Derecho y el orden jurídico internacional. En A. Zapata de Arbeláez (Comp.), Derecho internacional de los negocios: alcances (pp. 15-48). Bogotá: Universidad Externado de Colombia. 